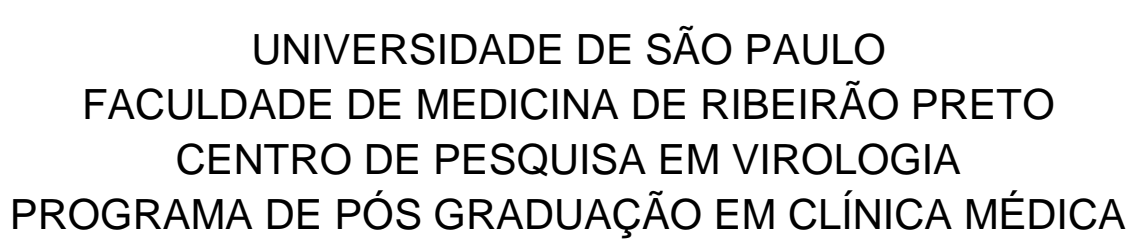

\title{
ANÁLISE DA PRESENÇA DE MUTAÇÕES NA SEQUÊNCIA DE NUCLEOTÍDEOS DO DOMÍNIO HOMO B DO GENE DA ENDOPROTEASE FURINA
}

Flávia Masson de Moraes

Orientador: Prof. Dr. Benedito Antônio Lopes da Fonseca

Ribeirão Preto

2016 
Análise da presença de mutações na sequência de nucleotídeos do domínio homo B do gene da endoprotease furina

\begin{abstract}
Dissertação de mestrado a ser apresentada ao curso de Pós-Graduação em Clínica Médica Investigação Biomédica da Faculdade de Medicina de Ribeirão Preto - Universidade de São Paulo, para a obtenção do título de Mestre em Ciências.
\end{abstract}

Orientador: Prof. Dr. Benedito Antônio Lopes da Fonseca

Ribeirão Preto 


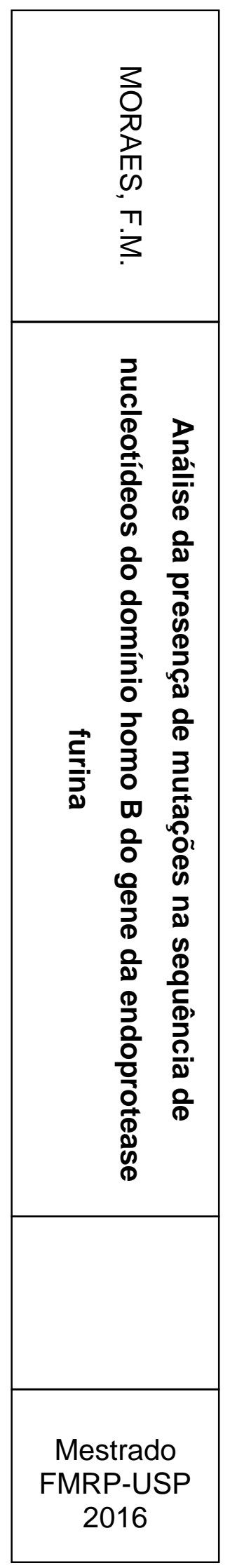




\title{
AUTORIZO A REPRODUÇÃO E DIVULGAÇÃO TOTAL OU PARCIAL DESTE
} TRABALHO, POR QUALQUER MEIO CONVENCIONAL OU ELETRÔNICO, PARA FINS DE ESTUDO DE PESQUISA, DESDE QUE CITADA A FONTE.

\author{
Catalogação na Publicação \\ Serviço de Documentação
}

Faculdade de Medicina de Ribeirão Preto da Universidade de São Paulo

Moraes, Flávia Masson de

Análise da presença de mutações na sequência de nucleotídeos do domínio homo $B$ do gene da endoprotease furina/ Flávia Masson de Moraes; orientador: Prof. Dr. Benedito Antônio Lopes da Fonseca - Ribeirão Preto, 2016.

54p: il; $30 \mathrm{~cm}$

Dissertação de Mestrado apresentada à Faculdade de Medicina de Ribeirão Preto da Universidade de São Paulo. Programa de Pós-Graduação em Clínica Médica Investigação Biomédica, 2016.

1. Furina 2. Mutação 3. Dengue 4. HRM 


\section{FOLHA DE APROVAÇÃO}

Nome: Flávia Masson de Moraes

Título: Análise da presença de mutações na sequência de nucleotídeos do domínio homo B do gene da endoprotease furina

Dissertação de Mestrado apresentada à Faculdade de Medicina de Ribeirão Preto da Universidade de São Paulo. Programa de Pós-Graduação em Clínica Médica - Investigação Biomédica.

Apresentada em

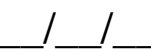

\section{Banca Examinadora}

Prof. Dr.

Instituição:

Assinatura:

Prof. Dr.

Instituição:

Assinatura:

Prof. Dr.

Instituição: Assinatura: 
DEDICATÓRIA

Dedico este trabalho aos meus pais, irmãos e à toda a minha família por me incentivarem a sempre seguir os meus sonhos. 


\section{AGRADECIMENTOS}

Agradeço em primeiro lugar ao professor Dr. Benedito por me acompanhar desde o começo da minha carreira científica, por me orientar e por permitir que eu faça parte do seu grupo de pesquisa.

Agradeço a todos os professores componentes da banca examinadora. Obrigada pela disponibilidade e pelo tempo dedicado à leitura e discussão desse trabalho.

Agradeço a todos os funcionários do Departamento de Clínica Médica, principalmente ao Emerson, por sempre tirar as minhas dúvidas e por me lembrar dos prazos.

Agradeço à CAPES pela bolsa e pelo financiamento desse projeto.

Agradeço aos funcionários, companheiros e amigos do Centro de Pesquisa em Virologia por todo aprendizado, pelas conversas, pelos almoços, cafés da tarde e pelas risadas diárias, especialmente aos amigos de laboratório Danillo, Taline, Beatriz, Michelli, Marcela e Jonathan, e também aos amigos que não estão mais com a gente Emiliana, Fernanda, Ana Luísa e Flávio.

Agradeço especialmente à Dra. Emiliana Abrão, que além de ser uma grande amiga é também uma grande orientadora, confidente e conselheira. Obrigada por sempre estar ali.

Agradeço à Dra. Miriã pela ajuda e por me ensinar a utilizar as ferramentas necessárias à análise dos sequenciamentos.

Agradeço imensamente aos meus pais por serem tão maravilhosos para mim e por me ensinarem que a educação é a melhor herança que alguém pode ter. Agradeço aos meus irmãos, avós e tios, por sempre me apoiarem e acreditarem em mim.

Agradeço ao meu namorado Wendell, quem nunca duvidou que eu conseguiria chegar até aqui. Obrigada por me ouvir, me apoiar e me fazer sorrir todos os dias.

Agradeço a todos aqueles que de alguma forma me ajudaram a ficar mais perto de realizar os meus sonhos. 
"A tarefa não é tanto ver aquilo que ninguém viu, mas pensar o que ninguém ainda pensou sobre aquilo que todo mundo vê." 


\section{RESUMO}

MORAES, F. M. Análise da presença de mutações na sequência de nucleotídeos do domínio homo B do gene da endoprotease furina. 2016. 54f. Dissertação (Mestrado). Faculdade de Medicina de Ribeirão Preto, Universidade de São Paulo, Ribeirão Preto.

Os vírus dengue (DENV) são os principais arbovírus (vírus transmitidos por artrópodes) circulantes no Brasil e são transmitidos por mosquitos do gênero Aedes, causando a doença denominada dengue. Atualmente, a dengue é a arbovirose humana de maior significância em saúde pública, existindo quatro diferentes sorotipos: DENV- 1 a 4 . Embora grande parte das infecções por dengue seja assintomática ou resultem em sintomas mais brandos, o número de pacientes com complicações ou com uma forma mais grave da doença tem aumentado significativamente a cada ano. Sabe-se que a presença de mutações no gene que codifica a endoprotease furina, produzida em uma grande diversidade de células humanas e essencial no processo de maturação dos vírus dengue nas células infectadas, levam à perda da atividade catalítica dessa proteína e, consequentemente, à deficiência na maturação viral. Esse trabalho teve como objetivo analisar a presença de mutações no domínio homo $B$ da furina e verificar se a gravidade da doença está ou não relacionada a elas. Para isso, 245 amostras de DNA, incluindo amostras de pacientes com dengue, dengue grave e controles, foram submetidas à reação de PCR em Tempo Real, análise por High Resolution Melting (HRM) e aquelas que apresentaram mutação, segundo esse método, foram sequenciadas. Os resultados mostraram que todas as amostras classificadas, por HRM, como diferentes variantes não apresentavam qualquer mutação por sequenciamento, o que pode ser devido à qualidade das amostras e à concentração de sal, já que esses são fatores determinantes para a eficiência do HRM. Como as amostras dos grupos dengue e dengue grave também foram sequenciadas e verificou-se que também não há mutações nas sequências dessas amostras, concluímos que a gravidade da dengue não está relacionada com a presença de mutações no domínio homo $B$ da endoprotease furina.

Palavras Chaves: Furina, Dengue, mutação, HRM 


\begin{abstract}
MORAES, F. M. Analysis of the presence of mutations in homo $B$ nucleotide sequence of endoprotease furin gene. 2016. 54f. Dissertation (Master). Faculdade de Medicina de Ribeirão Preto, Universidade de São Paulo, Ribeirão Preto.
\end{abstract}

Dengue viruses (DENV) are the main arboviruses (virus transmitted by arthropods) that circulate in Brazil and are transmitted by Aedes mosquitoes, causing dengue disease. Nowadays, dengue is the most important arbovirosis that affects humans and it is an important disease to public health. There are four dengue serotypes (DENV- 1 a 4) and, although the majority of dengue infections remain asymptomatic or cause milder symptoms, the number of patients with complications has increased year by year. It is known that the presence of mutations in furin gene, which is an important endoprotease produced in a high diversity of human's cells and is essential for dengue virus maturation, cause the loss of its catalytic activity and, consequently, leads to virus maturation deficiency. This work aimed the analysis of the presence of mutations in furin homo $B$ domain and the verification if dengue severity is related or not with them. Thus, 245 DNA samples, including patient's samples with dengue, severe dengue and control group, were amplified by Real Time PCR, analyzed by High Resolution Melting (HRM) and those with any mutation, using this method, were sequenced. The results have showed that all samples classified as different variants by HRM did not presented any mutation by sequencing, what might be due to samples quality and salt concentration, since these are determinant factors for HRM efficiency. Dengue and severe dengue samples were sequenced as well and no mutations were found. In conclusion, dengue severity is not related to the presence of mutations in homo B domain.

Key words: Furin, Dengue, mutation, HRM 


\section{LISTA DE FIGURAS}

Figura 1. Organização genômica dos vírus pertencentes ao gênero Flavivirus. (Adaptado de Barros, 2007).

Figura 2. Proteínas do vírus da dengue através da membrana do retículo endoplasmático. As setas indicam locais que sofrem clivagem por proteases (Adaptado de Li et al, 2008).

Figura 3. Ciclo replicativo dos vírus pertencentes ao gênero Flavivirus. Fonte: Pierson and Diamond, 2012.

Figura 4. Via de ativação da endoprotease furina. A furina madura e as porções do propeptídeo estão mostradas em rosa e preto, respectivamente. A primeira clivagem, RAKR (Arg-Ala-Lys-Arg), na região C-terminal do propeptídeo, e a segunda clivagem, RGVTKR (Arg-Gly-Val-Thr-Lys-Arg), no interior do propeptídeo, estão representadas. Modificado de Nakayama, 1997.

Figura 5. Gene da endoprotease furina. A região de clivagem RAKR, os resíduos catalíticos Asp, His, Ser e Asn (Asp) (D, H, N e S, respectivamente), bem como a sequência Arg-Gly-Asp (Ser) (RGD), são mostrados. Modificado de Nakayama, 1997.

Figura 6. Curvas de melting mostrando a diferença entre as curvas do homozigoto, heterozigoto e selvagem. Vermelho: homozigoto com guanina, verde: homozigoto com adenina, azul: heterozigoto. Modificado de A Guide to High Resolution Melting (HRM) Analysis, Applied Biosystems. 20

Figura 7. Gel de eletroforese mostrando parte da região do domínio homo B amplificada sob a temperatura de $60^{\circ} \mathrm{C}$. A. Na ordem: marcador de $1 \mathrm{~kb}$, controle negativo (neg) e amostra de DNA. B. Na ordem: marcador de $1 \mathrm{~kb}$ e algumas amostras de DNA de diferentes pacientes. .26

Figura 8. Gel de eletroforese mostrando o fragmento de 150 pb obtido após a realização de uma segunda PCR convencional. Na ordem: marcador de $100 \mathrm{pb}$, controle negativo (neg) e amostras de DNA purificado de diferentes pacientes. 27

Figura 9. Amostras dos grupos "Dengue" e "Dengue grave" analisadas por HRM. A. Aligned melt curves. B. Derivative melt curves. 28

Figura 10. Amostras do grupo "Controle" analisadas por HRM. A. Aligned melt curves. B. Derivative melt curves.

Figura 11. Alinhamento das amostras do grupo "Controle" com a sequência de RNA mensageiro da furina. Destaque da sequência de nucleotídeos referente aos aminoácidos "RGD". 
Figura 12. Cromatograma mostrando as inserções detectadas pelo sequenciamento. As setas indicam o pico referente à cada inserção. Azul: inserção do nucleotídeo G. Rosa: inserção do nucleotídeo A. Verde: inserção do nucleotídeo C.

Figura 13. Alinhamento das amostras dos grupos "Dengue" $e$ "Dengue grave" com a sequência de RNA mensageiro da furina. Destaque da sequência de nucleotídeos referente aos aminoácidos "RGD". 32

Figura 14. Sequências destacadas referentes ao aminoácido triptofano (Trp). A. Amostras do grupo "Controle". B. Amostras dos grupos "Dengue" e "Dengue grave". 


\section{LISTA DE TABELAS}

Tabela 1. Sequências dos primers desenhados. 23

Tabela 2. Valor do Silhouette Score das amostras classificadas como mutantes pelo HRM. Em vermelho estão as amostras que obtiveram valor menor que 0.8 ...34 


\title{
LISTA DE ABREVIATURAS/SIGLAS
}

\author{
ADE - Antibody Dependent Enhancement \\ BRAF - Proto-oncogene B-Raf \\ C - Proteína do capsídeo \\ DC - Dengue clássica \\ DC-SIGN - Dendritic cell-specific \\ DENV - Dengue vírus \\ DNA - Ácido desoxirribonucleico \\ E - Proteína do envelope \\ ELISA - Enzyme Linked Immunosorbent Assay \\ Fc - Crystal Fraction \\ FHD - Febre hemorrágica da dengue \\ FMRP - Faculdade de Medicina de Ribeirão Preto \\ $\mathrm{HCl}$ - Ácido Clorídrico \\ HCRP - Hospital das Clínicas de Ribeirão Preto \\ HRM - High Resolution Melting \\ IgG - Imunoglobulina G \\ IgM - Imunoglobulina M \\ LoVo - Células de adenocarcinoma humano \\ M - Proteína de membrana \\ NS - Proteína não-estrutural \\ PC - Proteína convertase \\ PCR - Reação em Cadeia da Polimerase \\ $\mathrm{pH}$ - Potencial hidrogeniônico \\ prM - Proteína precursora da membrana \\ RNA - Ácido Ribonucleico \\ SCD - Síndrome do choque da dengue \\ UE - Unidade de Emergência
}




\section{SUMÁRIO}

RESUMO

ABSTRACT

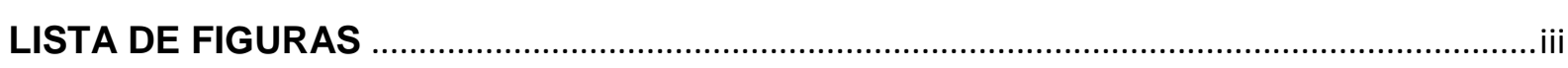

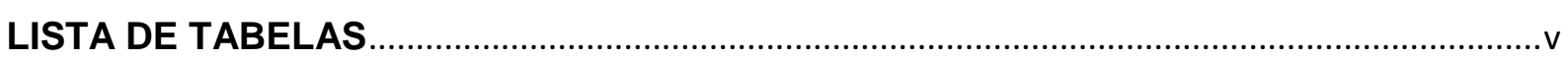

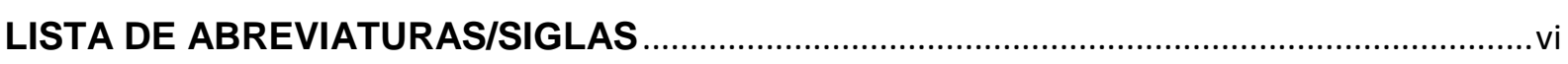

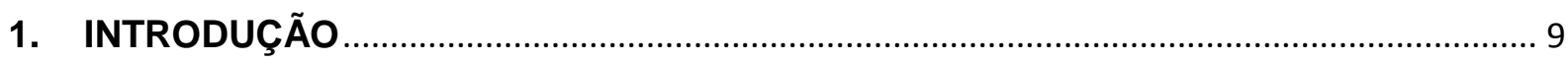

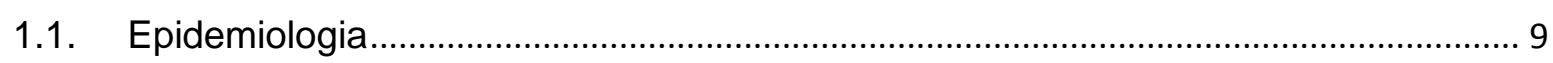

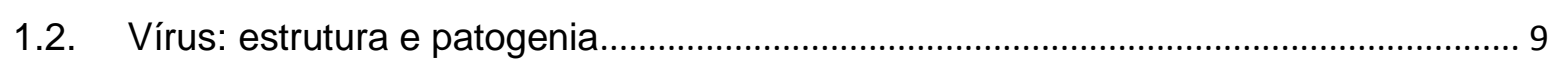

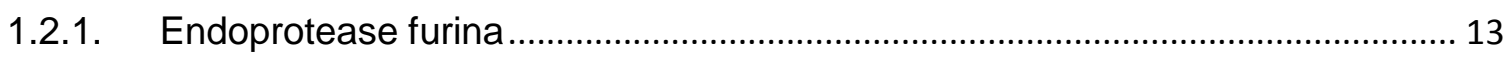

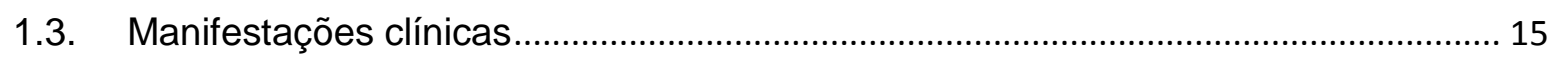

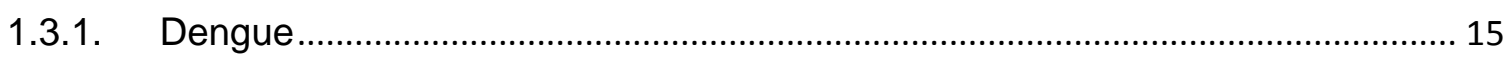

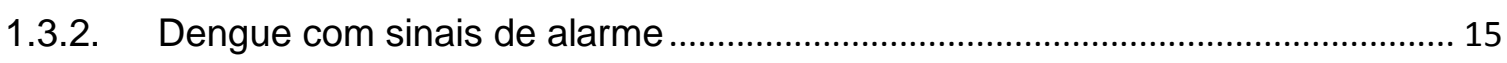

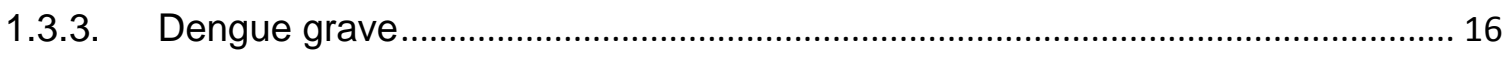

1.4. Diagnóstico, tratamento e prevenção...................................................................... 16

1.5. High Resolution Melting (HRM) ............................................................................ 18

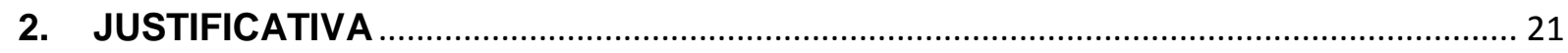

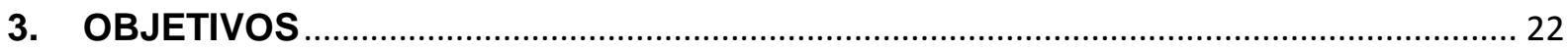

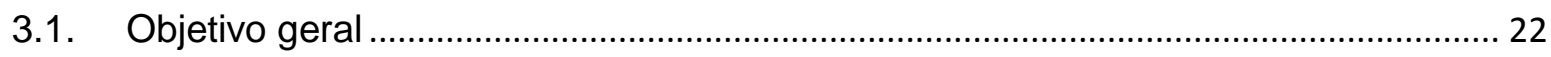

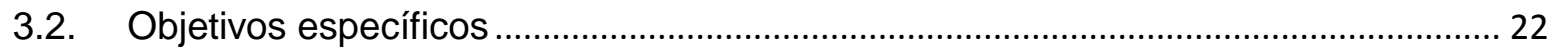

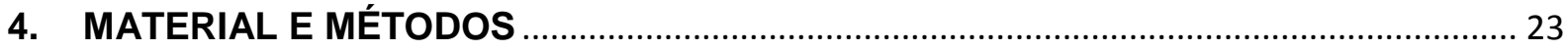

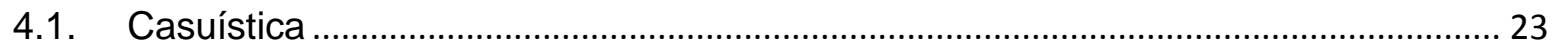

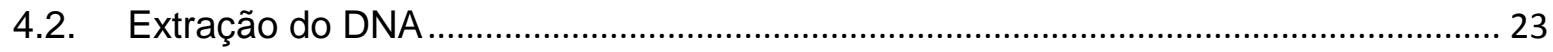

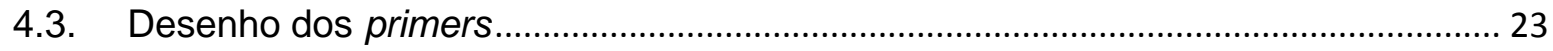

4.4. Amplificação do domínio homo B por PCR em Tempo Real....................................... 24

4.4.1. Padronização da reação por PCR convencional .................................................... 24

4.4.2. Purificação do DNA a partir do gel de agarose ................................................... 24

4.4.3. Padronização da reação de PCR em Tempo Real ............................................... 24

4.4.4. Análise por High Resolution Melting (HRM) ....................................................... 24

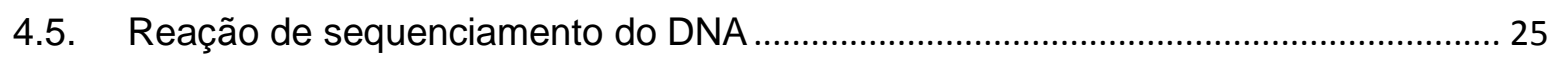

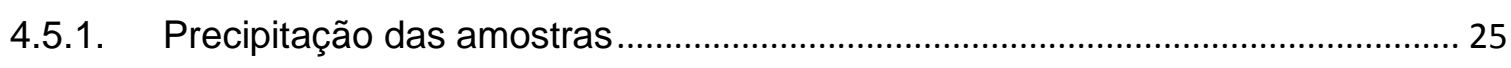

4.6. Análise das sequências genômicas .............................................................................. 25

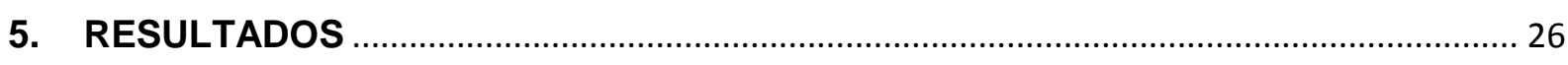

5.1. Padronização da reação por PCR convencional ...................................................... 26 
5.2. Purificação do DNA a partir do gel de agarose ......................................................... 26

5.3. PCR em Tempo Real e análise por HRM ................................................................. 27

5.4. Sequenciamento das amostras selecionadas por HRM ............................................ 30

5.4.1. Sequenciamento das amostras dos grupos "Dengue" e "Dengue grave" ......... 31

5.4.2. Análise de outras mutações por sequenciamento ................................................ 32

5.5. Análise da qualidade da genotipagem pelo valor do Silhouette Score..................... 34

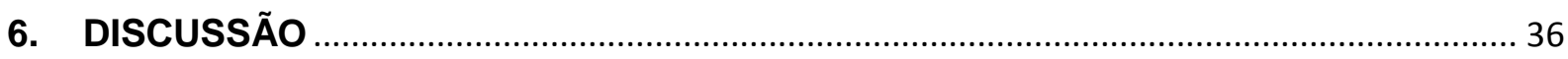

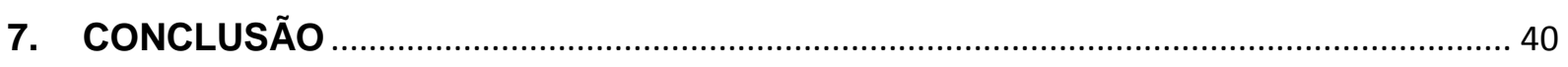

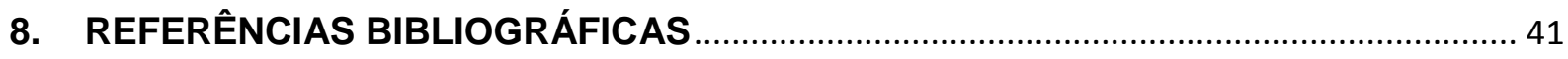




\section{INTRODUÇÃO}

\subsection{Epidemiologia}

A dengue é uma importante arbovirose que tem altos índices de morbidade e mortalidade na grande maioria dos países tropicais e subtropicais (Cansanção et al, 2015; Halstead, 1997), uma vez que o meio ambiente dessas regiões favorece o desenvolvimento e a proliferação do seu principal vetor, o mosquito Aedes aegypti (Guia de Vigilância Epidemiológica, 2005).

Nos últimos 50 anos, a incidência da doença aumentou em 30 vezes, havendo uma expansão das áreas afetadas. Estima-se que 290 milhões de infecções ocorram anualmente, sendo as Américas e a Ásia áreas altamente endêmicas (Bhatt et al, 2013). Embora grande parte das infecções por dengue seja assintomática ou resultem apenas em doença febril de gravidade leve a moderada, o número de pacientes com complicações ou com uma forma mais grave da doença tem aumentado significativamente a cada ano (Rodenhuis-Zybert, 2011).

Do início de janeiro ao final de abril de 2016 foram registrados 1.054 .127 casos prováveis de dengue no país, com a região Sudeste dominando o número de casos prováveis $(59,3 \%)$, seguida da região Nordeste (19,5\%). Foram confirmados 340 casos de dengue grave, 3.626 casos de dengue com sinais de alarme e 190 óbitos por dengue. Ainda, o isolamento viral de 1.124 amostras mostrou que, até esse período, a maioria dos casos confirmados pertenciam ao sorotipo DENV-1 (Boletim epidemiológico - Guia de vigilância em saúde, 2016).

\subsection{Vírus: estrutura e patogenia}

A dengue é causada por um vírus do gênero Flavivirus, pertencente à família Flaviviridae. Esse gênero é composto por 53 espécies virais, sendo, em sua maioria, arbovírus, ou seja, após um ciclo replicativo no organismo do vetor, os vírus são transmitidos por artrópodes (Mackenzie, 2004). O genoma dos flavivírus consiste de uma fita simples de RNA de polaridade positiva, com aproximadamente $11 \mathrm{~kb}$ de extensão, traduzida em uma única poliproteína viral que é clivada, durante e após a tradução, por proteases de origem viral e também da célula hospedeira, como ilustrado na figura 1. 


\section{Flavivirus}

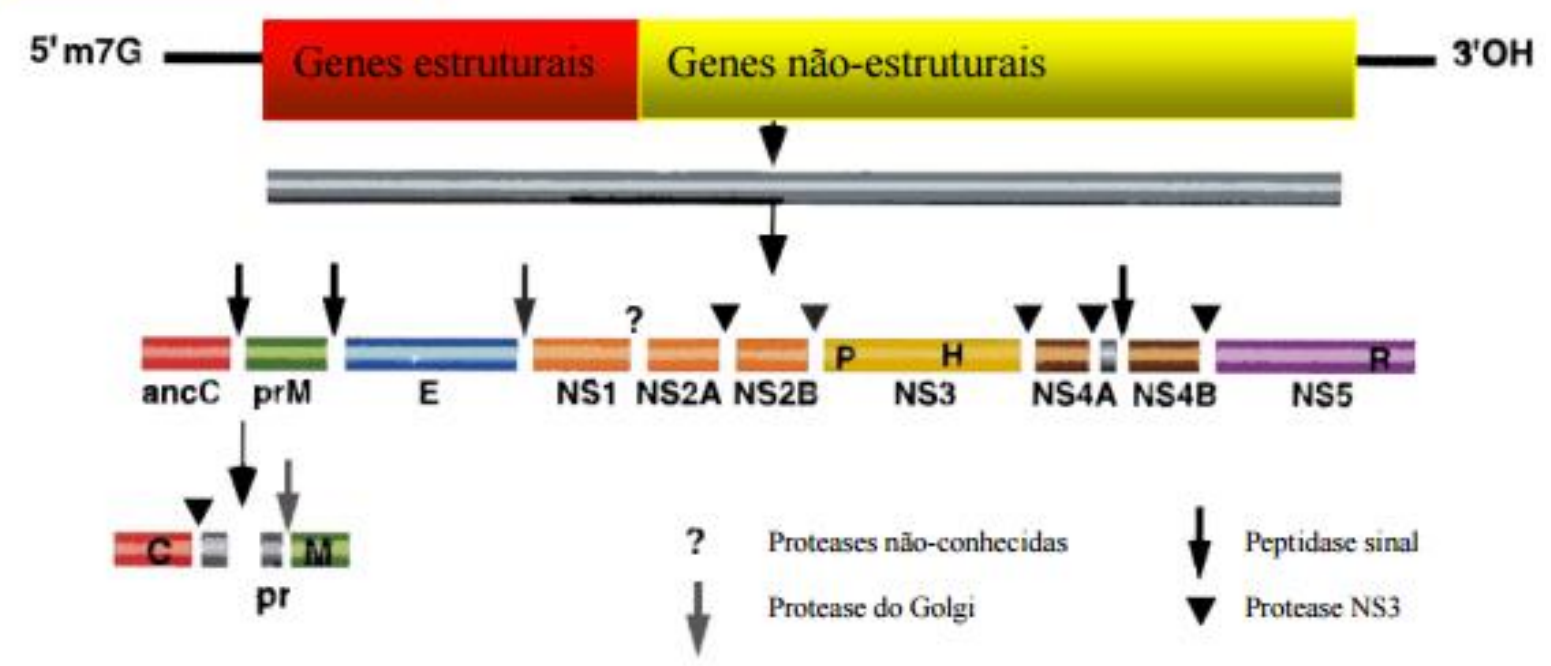

Figura 1. Organização genômica dos vírus pertencentes ao gênero Flavivirus. (Adaptado de Barros, 2007).

Após a clivagem da poliproteína, resultam 3 proteínas estruturais: a do capsídeo (C), que circunda o genoma do vírus, a precursora da membrana (prM) e a do envelope $(E)$, sendo que as duas últimas encontram-se na bicamada lipídica do envelope viral (Kelly et al, 2000; Halstead, 2008), como pode ser visto na figura 2. Além delas, 7 proteínas não estruturais também são produzidas, sendo elas NS1, NS2a, NS2b, NS3, NS4a, NS4b e NS5. As extremidades desse genoma possuem sequências curtas não codificadoras nas extremidades denominadas 3'-NC e 5'-NC e as sequências codificadoras são organizadas na seguinte ordem: 5'-C-prM-E-NS1NS2a-NS2b-NS3-NS4a-NS4b-NS5-3' (Gubler \& Markoff, 2007). 


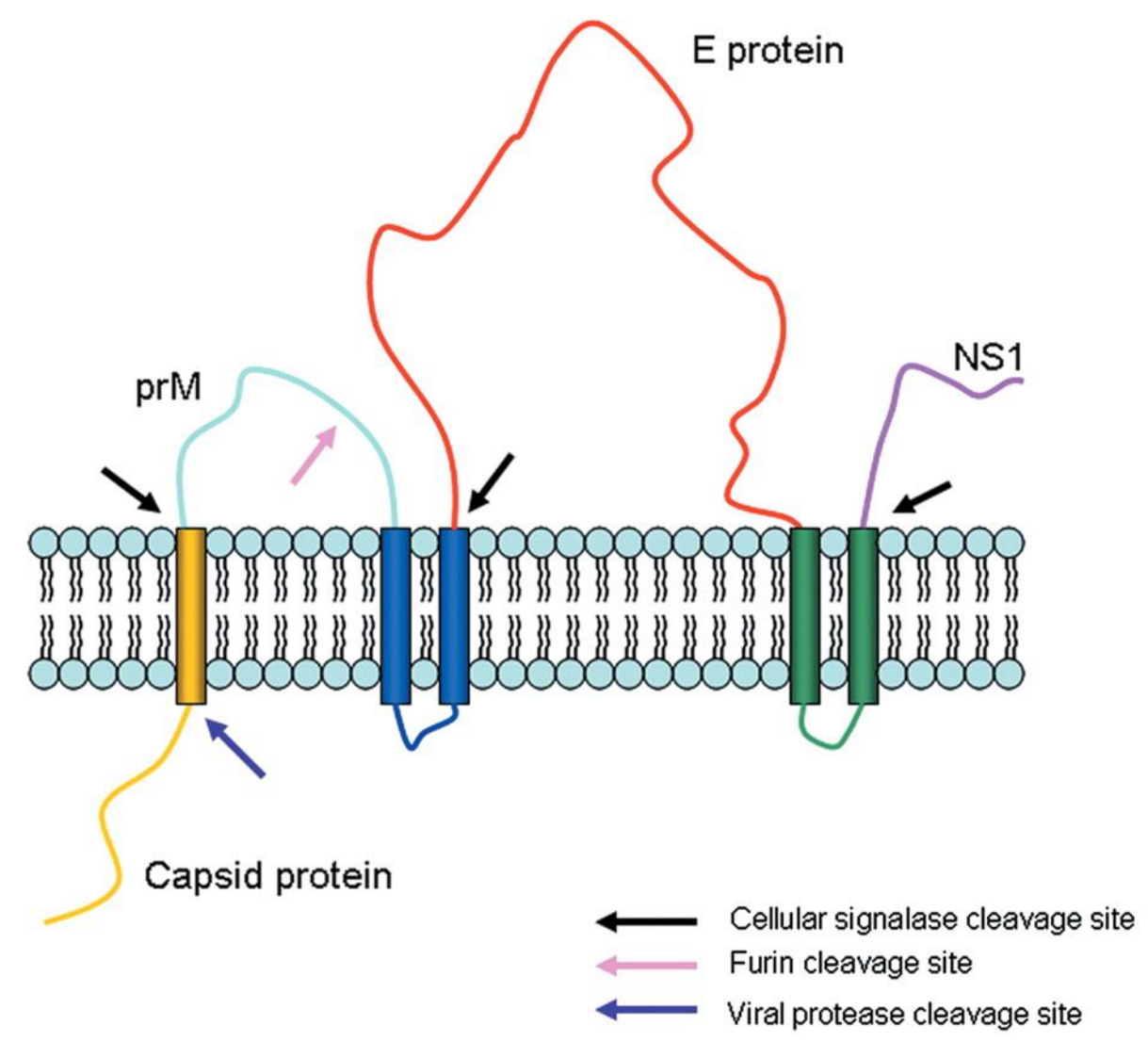

Figura 2. Proteínas do vírus da dengue através da membrana do retículo endoplasmático. As setas indicam locais que sofrem clivagem por proteases (Adaptado de Li et al, 2008).

A figura 3 mostra o ciclo replicativo dos flavivírus. Após sua ligação à superfície celular, o vírus é endocitado e entregue a endossomos, cujo baixo $\mathrm{pH}$ gera uma mudança conformacional na glicoproteína $\mathrm{E}$, o que permite a fusão do vírus com a membrana celular do endossomo e a liberação dos componentes virais no citoplasma celular (Henchal \& Putnak, 1990; Rey, 2003). Já a proteína prM é clivada em proteína de Membrana (M) por uma furino-protease, o que a torna madura e permite que as porções da proteína $\mathrm{E}$ que se projetam do vírus fiquem evidenciadas, ocorrendo a saída do vírus por exocitose (Modis et al, 2003). Tal clivagem da prM é de grande importância para a infectividade viral, pois partículas imaturas não se fundem com as membranas celulares e, consequentemente, não há liberação dos componentes virais (Henchal \& Putnak, 1990). 


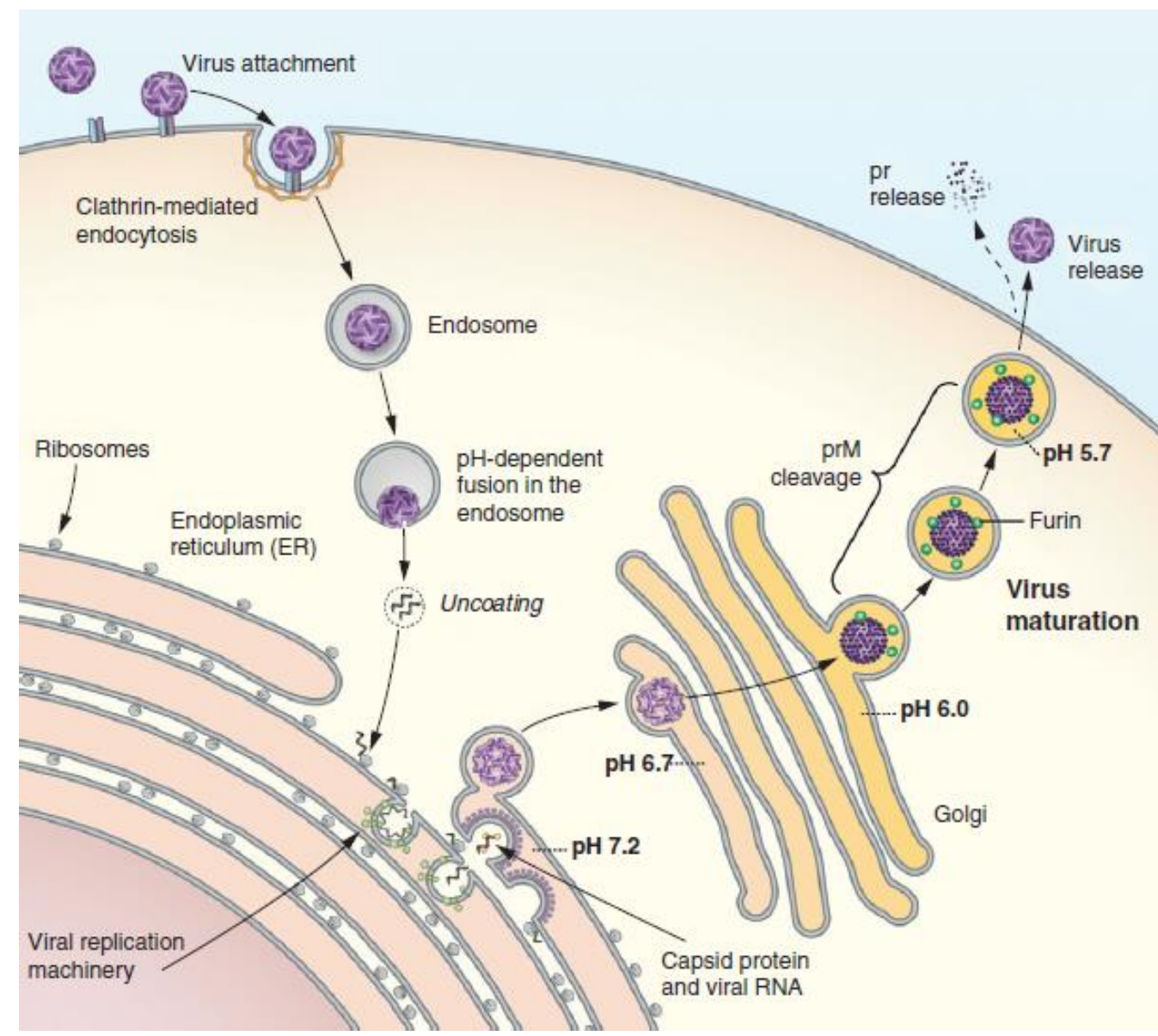

Figura 3. Ciclo replicativo dos vírus pertencentes ao gênero Flavivirus. Fonte: Pierson and Diamond, 2012.

São conhecidos quatro sorotipos dos vírus dengue, que apresentam características antigênicas distintas: DENV-1, DENV-2, DENV-3 e DENV-4 (Tauil, 2001). Tais sorotipos distinguem-se por anticorpos neutralizantes produzidos pelo organismo em resposta à infecção (Stephenson, 2005). Sabe-se que a resposta imune contra a infecção pelos vírus da dengue atua, principalmente, contra as proteínas prM e E. Porém, muitos estudos mostram que essa resposta nas infecções primárias e secundárias é predominantemente contra a proteína $\mathrm{E}$ (Rodenhuis-Zybert et al, 2011). Essa proteína é de grande importância, pois além de induzir a resposta imune do hospedeiro, ela medeia a entrada do vírus na célula. Vários candidatos tem sido sugeridos como receptores primários para o vírus, como as moléculas DC-SIGN, heparan sulfato e o receptor de manose (Chen et al 1997; Miller et al 2008; Tassaneetrithep et al 2003).

As proteínas $\mathrm{E}$ e prM (M) podem neutralizar completamente o mesmo sorotipo ou aumentar a entrada de partículas virais nas células na infecção por um sorotipo 
diferente, pelo processo denominado Antibody Dependent Enhancement of Infection (ADE) (Halstead, 2008; Rodenhuis-Zybert, 2011). Neste fenômeno, os vírus, utilizando-se de anticorpos pré-existentes e sub-neutralizantes produzidos por uma infecção anterior, ligam-se às células alvo portadoras de receptores $\mathrm{Fc}$, aumentando a sua capacidade de infecção por meio de rota natural receptor-ligante. Dessa maneira, a quantidade de vírus torna-se exacerbada, assim como a gravidade da doença (Halstead, 2008; Rodenhuis-Zybert et al, 2011; Tirado \& Yoon, 2003).

Rodenhuis-Zybert e colaboradores (Rodenhuis-Zybert et al, 2010) mostraram que partículas de DENV imaturas tornam-se infecciosas na presença de anticorpos anti-prM. Durante a infecção primária, ou seja, quando não há anticorpos contra os antígenos virais, as partículas imaturas não conseguem infectar as células do hospedeiro. Porém, numa infecção secundária, agora com anticorpos contra o vírus, incluindo anti-prM, tais partículas imaturas podem se tornar altamente infecciosas, uma vez que a associação destas com anticorpos anti-prM facilita a infecção por meio da ligação Fcyll-receptor e aumenta o título de vírus circulante no hospedeiro, podendo levar ao aparecimento de dengue grave.

Ainda, Rodenhuis-Zybert e colaboradores (Rodenhuis-Zybert et al, 2010) mostraram que a furina tem papel essencial nesse processo. As partículas imaturas na presença de anticorpos anti-prM e ausência de furina ativa não são infecciosas, mas quando na presença dessa endoprotease, o processamento da prM em proteína de membrana faz com que as partículas tornem-se altamente infecciosas. Isso evidencia a importância da furina, uma vez que numa condição em que ela perde sua função, devido à alguma mutação por exemplo, mesmo que se tenham partículas imaturas associadas a anticorpos de uma infecção primária, essas partículas não iriam infectar as células do hospedeiro, o que reduziria a chance de desenvolver dengue grave.

\subsubsection{Endoprotease furina}

A proteína glicosilada prM é encontrada como um heterodímero com a proteína E em partículas imaturas do vírus e pode atuar como uma chaperona para 0 dobramento correto da proteína $\mathrm{E}$, além de prevenir a degradação dessa proteína durante o seu processamento pós-traducional. Ao final da via trans-Golgi, a prM é clivada, em pH baixo, pela furina, uma endoprotease do hospedeiro, resultando na 
proteína $\mathrm{M}$, não-glicosilada, permitindo assim uma mudança conformacional no heterodímero proteína E/prM, o que torna a partícula viral madura e expõe a proteína E, possibilitando assim, a saída de partículas virais infecciosas (Halstead, 2003).

A figura 4 ilustra a via de ativação da furina. Antes de tornar-se ativa, essa endoprotease sofre um processo de clivagem autocatalítica no interior do retículo endoplasmático, por meio do qual ocorre a clivagem do propeptídeo na região ArgAla-Lys-Arg (RAKR) dessa proteína. Esse fenômeno é essencial para que se tenha a saída da furina do retículo endoplasmático (Anderson et al, 2002). Ao atingir a região trans-Golgi, ambiente ácido e rico em íons de cálcio, o propeptídeo, que permanece associado à furina apesar de ter sido clivado, sofre uma segunda clivagem, agora na região Arg-Gly-Val-Thr-Lys-Arg (RGVTKR), e é liberado, o que torna a furina biologicamente ativa (Nakayama, 1997).

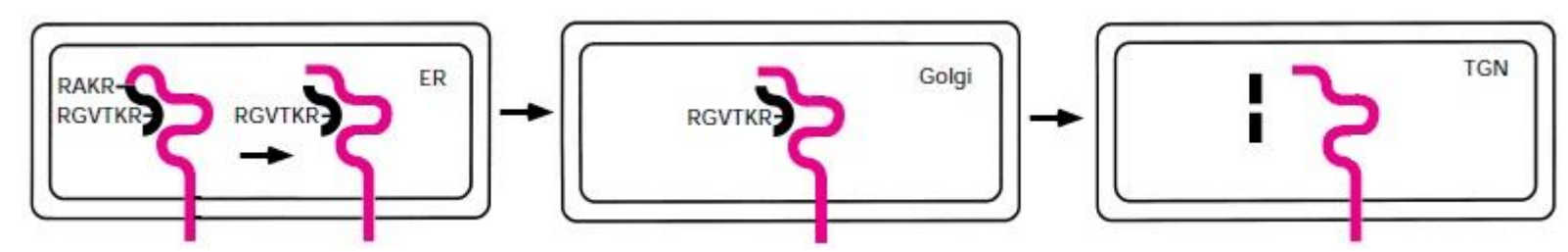

Figura 4. Via de ativação da endoprotease furina. A furina madura e as porções do propeptídeo estão mostradas em rosa e preto, respectivamente. A primeira clivagem, RAKR (Arg-Ala-Lys-Arg), na região C-terminal do propeptídeo, e a segunda clivagem, RGVTKR (Arg-Gly-Val-Thr-Lys-Arg), no interior do propeptídeo, estão representadas. Modificado de Nakayama, 1997.

O gene que codifica essa endoprotease está localizado no cromossomo 15q26.1 (Lei et al, 2009). Tal gene, representado na figura 5, apresenta um domínio chamado "homo B", o qual é essencial para a atividade endoproteolítica da furina, assim como o domínio catalítico (Takahashi et al, 1995). No interior desse domínio, existe uma sequência conservada entre as convertases da família das proprotein convertases, da qual a furina faz parte. Tal sequência é constituída por três aminoácidos: Arg-Gly-Asp (RGD) (Nakayama, 1997). Lusson e colaboradores (1997) mostraram que mutações nessa sequência em $\mathrm{PC1/PC3}$, convertases pertencentes à mesma família da furina, levam à perda da sua atividade catalítica. 


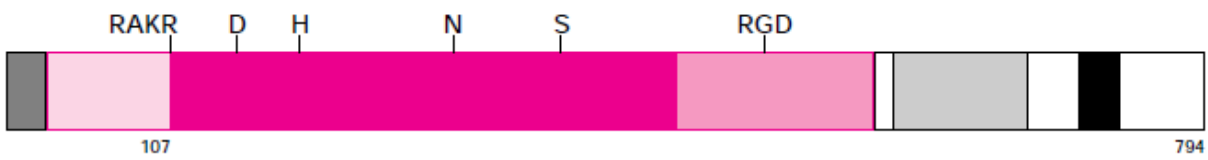

Figura 5. Gene da endoprotease furina. A região de clivagem RAKR, os resíduos catalíticos Asp, His, Ser e Asn (Asp) (D, H, N e S, respectivamente), bem como a sequência Arg-Gly-Asp (Ser) (RGD), são mostrados. Modificado de Nakayama, 1997.

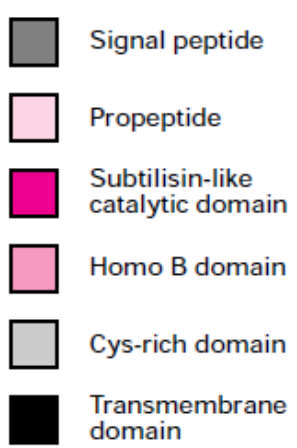

\subsection{Manifestações clínicas}

Até o final do ano de 2009, a classificação vigente das manifestações clínicas da dengue era aquela proposta pela Organização Mundial da Saúde, segundo a qual essa doença poderia ser classificada como dengue clássica (DC) e febre hemorrágica da dengue (FHD), sendo que esta última poderia apresentar quatro graus (I, II, III e IV), com FHD III e IV compreendendo a síndrome do choque da dengue (SCD) (WHO, 2005). Entretanto, desde janeiro de 2014 a nova classificação proposta pela Organização Mundial da Saúde entrou em vigor no Brasil. Segundo ela, a dengue passou a ter três classificações: dengue, dengue com sinais de alarme e dengue grave. Essa nova denominação mostrou-se mais sensível para captar os casos graves e, dessa maneira, deverá contribuir para melhorar o diagnóstico e reduzir a letalidade por dengue (Informe Semanal Dengue - Governo do Estado do Ceará, Secretaria da Saúde, 2013).

\subsubsection{Dengue}

Casos suspeitos de dengue devem ser considerados em pessoas que vivem em locais endêmicos ou que viajaram para algum desses locais, além da presença de febre e de pelo menos dois dos sintomas a seguir: náusea, vômito, manchas vermelhas na pele, leucopenia, dor nas articulações e "prova do laço" positiva (WHO, 2009).

\subsubsection{Dengue com sinais de alarme}

Manifestações clínicas como as mostradas no tópico 1.3.1. somadas a um ou mais dos sintomas a seguir levam à suspeita de dengue com sinais de alarme: dor 
abdominal, vômitos persistentes, sangramento das mucosas, acumulação de fluidos, letargia e aumento do fígado. O aumento do nível do hematócrito concomitante com a diminuição de plaquetas também é considerado um sinal de alarme (WHO, 2009).

\subsubsection{Dengue grave}

A dengue grave deve ser considerada em pessoas de áreas endêmicas com febre de 2 a 7 dias somada a algum dos seguintes sintomas: evidência de vazamento de plasma, sangramento, níveis alterados de consciência, envolvimento gastrointestinal grave e acometimento de órgãos (WHO, 2009).

\subsection{Diagnóstico, tratamento e prevenção}

O método padrão para o diagnóstico laboratorial da dengue é o isolamento viral, existindo quatro formas de realização desse procedimento: inoculação intracerebral em camundongos recém-nascidos, inoculação intratorácica em mosquitos adultos, cultura de células de mamíferos e cultura de células de mosquito. Porém, por ser uma técnica que demanda tempo, de 7-14 dias, ela acaba não sendo a mais recomendada para uso em laboratórios de rotina (Guzmán \& Kourí, 1996; Gubler, 1998). Por isso, outras formas de diagnóstico da dengue são mais utilizadas, sendo elas a detecção de anticorpos no soro de pacientes e a detecção de antígenos virais ou de seu genoma (Halstead, 2008). Dentre os principais testes utilizados, merece destaque 0 imunoensaio ELISA (Enzyme-Linked Immunosorbent Assay), por meio do qual é possível diferenciar a infecção primária da infecção secundária, detectando-se diferentes níveis de anticorpos $\lg M$ e lgG, respectivamente.

Existem, também, testes rápidos (até 20 minutos) e de menor custo, como a imunocromatografia, que detectam a presença de antígenos ou anticorpos no soro de pacientes. No caso dos anticorpos, quando presentes, reagem com um antígeno comum a todos os sorotipos, presente em uma coluna fornecida pelo kit diagnóstico. Ainda, é possível detectar a proteína NS1 no soro de pacientes, por meio da reação desta com anticorpos IgM e lgG anti-NS1 presentes na coluna de imunocromatografia (Cardosa et al, 1988). Além disso, dentre os métodos moleculares para detecção do genoma viral, temos a reação em cadeia da polimerase (PCR) que também pode ser utilizada no diagnóstico da dengue, assim como a PCR em Tempo Real (Timerman et 
al, 2012). Porém, as técnicas moleculares ainda são pouco utilizadas para investigação de casos suspeitos fora dos centros de pesquisa e universidades devido ao alto custo para o uso rotineiro nos serviços de saúde.

Com relação ao tratamento da doença, não existe nenhum medicamento que esteja relacionado com a eliminação do vírus do organismo do paciente. A atenção aos sintomas é a única forma de tratar o indivíduo doente, sendo a hidratação via oral ou venosa, a administração de antipiréticos e de analgésicos adequados as únicas formas de tratar o paciente e de evitar a piora do quadro. Além disso, é de extrema importância o monitoramento laboratorial por meio de exames de sangue daqueles pacientes com formas mais graves (WHO, 2009).

Já as vacinas têm recebido grande destaque para o combate de algumas doenças transmitidas por flavivírus como a febre amarela, a encefalite japonesa e a encefalite transmitida por carrapato. Entretanto, a elaboração de uma vacina contra a dengue ainda é um desafio (Stephenson, 2005). Isso se deve ao fato de a infecção com um dos sorotipos não provocar a imunidade contra os outros tipos, induzindo, apenas, a imunidade homóloga (Calvert et al, 2005). Assim sendo, é necessário que as possíveis vacinas contra a dengue sejam polivalentes, o que dificulta o seu desenvolvimento. Outro desafio está relacionado à ausência de modelos animais para se testar a efetividade das vacinas, uma vez que a doença não se manifesta de maneira semelhante em animais não humanos (Bricks, 2004). Além disso, o fenômeno do ADE também é uma dificuldade a ser enfrentada.

Apesar das dificuldades, diversas estratégias têm sido empregadas na tentativa de elaboração de uma vacina contra a dengue, como: as clássicas (vírus vivos atenuados em cultura de tecidos; partículas virais inativadas e vacinas de subunidades de proteínas ou peptídeos); as de tecnologia do DNA recombinante (vacinas quiméricas caracterizadas pela inserção de genes de um ou mais sorotipos do vírus da dengue no genoma de outros flavivírus ou em um sorotipo atenuado do vírus e uso de vetores capazes de expressar proteínas ou peptídeos), as vacinas de DNA e as mistas (associação de vírus vivos com proteínas ou partes do genoma viral) (Bricks, 2004). Dentre as técnicas existentes, a produção de vacinas que se utilizam de proteínas recombinantes mostra-se muito vantajosa, uma vez que o patógeno é excluído da vacina, o que elimina o risco de reversão ao genótipo virulento ou de inativação incompleta do organismo (Liljeqvist \& Stahl, 1999). 
Para que seja viável, a vacina deve proteger contra a infecção pelos quatro sorotipos virais e, nos países onde a dengue é endêmica, deve ser segura para uso em crianças entre 9-12 meses de idade, possuir baixo custo e ser capaz de induzir imunidade protetora a longo prazo (Heinz \& Stiasny, 2012; Halstead \& Deen, 2002). A ausência de uma vacina faz com que a única forma de se prevenir a dengue seja por meio da eliminação do vetor Aedes aegypti, o que é conseguido eliminando água parada de recipientes e cobrindo caixas d'água e piscinas, locais onde as larvas se desenvolvem.

Recentemente, a empresa farmacêutica Sanofi Pasteur desenvolveu uma vacina tetravalente contra a dengue, a qual se mostrou eficaz quando utilizada em três doses (0, 6 e 12 meses) (Capeding et al, 2014). A primeira campanha de vacinação começou no início de 2016 nas Filipinas, sendo vacina da Sanofi Pasteur a primeira a receber a aprovação para prevenção da dengue (Acesso online: www.es.dengue.info/).

\subsection{High Resolution Melting (HRM)}

O HRM é um método de análise pós-PCR utilizado para identificar variações genéticas nas sequências de ácidos nucleicos. Toda a análise se baseia na curva de melting (curva gerada por um gráfico de fluorescência liberada em função da temperatura), que é gerada após a PCR em Tempo Real quando se utiliza um fluoróforo intercalante de dupla fita (Taylor, 2009).

Inicialmente, a sequência de interesse é amplificada por PCR na presença de um fluoróforo saturante que se liga à dupla fita de DNA (Erali et al, 2008). Porém, na presença de alguma mutação na sequência de nucleotídeos, as moléculas do fluoróforo deixam o DNA no local onde há mutação, o que é visualizado por meio da diminuição do sinal de fluorescência, diferente do que ocorre com fluoróforos intercalantes não saturantes de dupla fita, que quando se deparam com uma mutação na sequência de DNA, não são liberados, havendo um rearranjo das moléculas desses fluofóforos na dupla fita de tal forma que não há mudança no sinal de fluorescência. Ao término da amplificação das sequências de interesse, a dupla fita do amplicon se dissocia gradativamente com o aumento da temperatura, gerando a curva de melting e, finalmente, a fluorescência emitida é medida no termociclador ( $A$ Guide to High Resolution Melting (HRM) Analysis, Applied Biosystems). 
Alguns fatores são determinantes para a realização da análise pós-PCR utilizando o HRM, sendo eles a qualidade da amostra, os primers utilizados na reação de PCR e o tamanho do amplicon. É importante que se tenha amostras com uma alta concentração de ácidos nucleicos, além de uma baixa concentração de sal, consequente da extração do material genético (A Guide to High Resolution Melting (HRM) Analysis, Applied Biosystems).

Ainda, os primers utilizados precisam ser altamente específicos para a região de interesse, sem a formação de dímeros. Por isso, é muito importante padronizar a concentração de cada primer utilizado na reação (HRM Experiments - User guide, Applied Biosystems). Fragmentos com tamanho entre 100-300 pb tem sido utilizados para a detecção de mutações de maneira bem sucedida (Gundry et al, 2003). Foi observado que quanto maior o tamanho do amplicon, menor é a diferença entre as curvas de melting de uma amostra selvagem e de uma amostra heterozigota, o que dificulta a separação entre elas (Reed \& Wittwer, 2004).

As curvas de melting geradas são diferenciadas de duas formas, como mostra a figura 6: a do homozigoto mutante, quando comparada com a amostra selvagem, tem a mesma forma da curva, mas diferente temperatura de melting. Já a do heterozigoto tem a forma da curva diferente quando comparado com a amostra selvagem (Taylor, 2009).

A confiabilidade no agrupamento correto das amostras e das curvas geradas é medida pelo Silhouette Score, que determina quão bem as amostras foram separadas entre os diferentes grupos (heterozigoto e homozigoto), sendo uma medida da qualidade da genotipagem. O valor ideal do Silhouette Score é entre 0.8 e 1.0 e esses valores são calculados e gerados pelo próprio software HRM ( $A$ Guide to High Resolution Melting (HRM) Analysis, Applied Biosystems). 


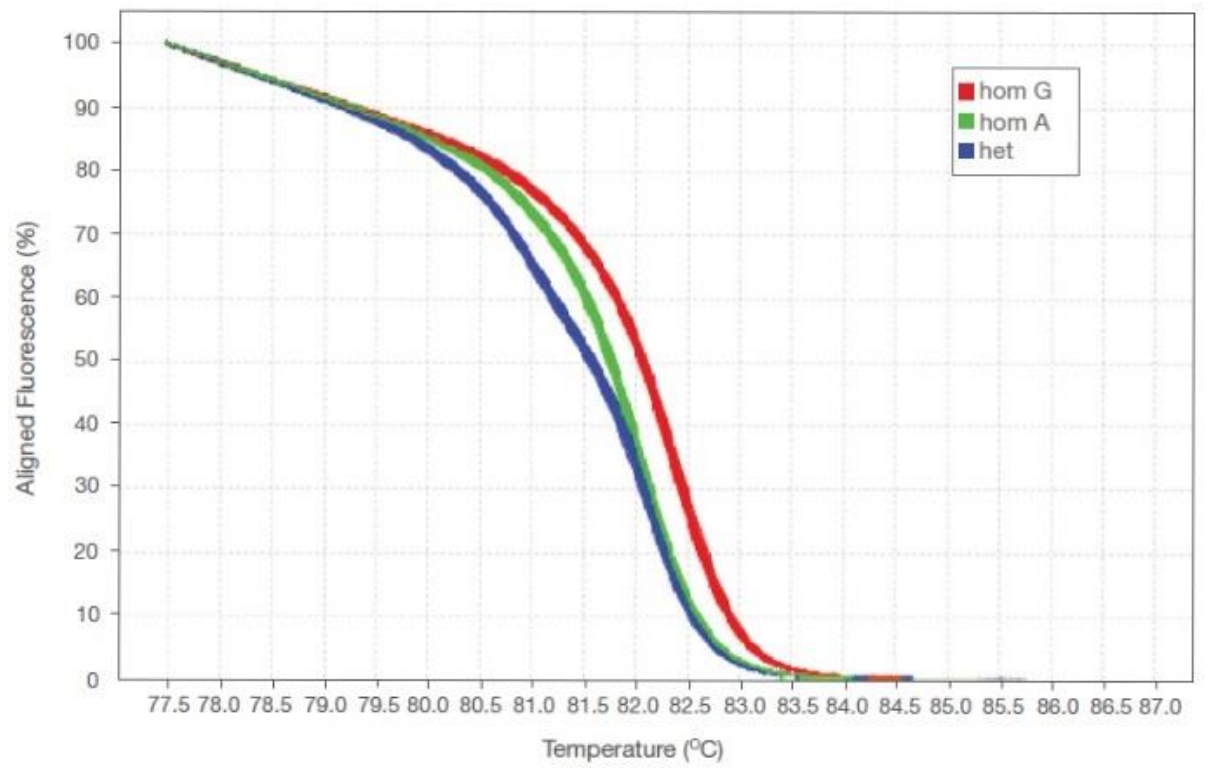

Figura 6. Curvas de melting mostrando a diferença entre as curvas do homozigoto, heterozigoto e selvagem. Vermelho: homozigoto com guanina, verde: homozigoto com adenina, azul: heterozigoto. Modificado de A Guide to High Resolution Melting (HRM) Analysis, Applied Biosystems. 


\section{JUSTIFICATIVA}

A furina é uma endoprotease essencial no ciclo de replicação dos vírus da dengue, uma vez que a clivagem da proteína prM por essa endoprotease torna as partículas virais maduras e capazes de serem liberadas da célula. Alguns trabalhos mostram a relação da presença de mutações no gene da furina com a perda da sua atividade catalítica. A dengue é uma doença que exibe três tipos de manifestações clínicas: dengue, dengue com sinais de alarme e dengue grave. Assim sendo, o presente trabalho buscou, por meio de técnicas moleculares, a análise da presença de mutações no domínio homo $B$, relacionado com a atividade catalítica da furina, na tentativa de associar mutações no gene desta proteína às diferentes manifestações clínicas da dengue. Além disso, não há na literatura nenhum trabalho que relaciona a presença de mutações nessa região com a gravidade da dengue, existindo apenas estudos comprovando a perda da atividade catalítica na furina mutada e a formação de partículas virais imaturas nessas mesmas condições. 


\section{OBJETIVOS}

\subsection{Objetivo geral}

Verificar a presença de mutações no domínio homo B do gene codificante da endoprotease furina.

\subsection{Objetivos específicos}

1. Realizar HRM com todas as amostras de DNA e selecionar aquelas que apresentarem mutação na região de interesse;

2. Sequenciar as amostras selecionadas por HRM e fazer a análise das mutações encontradas. 


\section{MATERIAL E MÉTODOS}

\subsection{Casuística}

Foram obtidas 23 amostras de pacientes com dengue e 11 com dengue grave, sendo que algumas já estavam com o DNA extraído e armazenado no Centro de Pesquisa em Virologia da Faculdade de Medicina de Ribeirão Preto (FMRP), e outras tiveram o DNA extraído a partir do sangue total. Além disso, 211 amostras de DNA de pacientes controles foram obtidas na Unidade de Emergência (UE) do Hospital das Clínicas de Ribeirão Preto (HCRP), incluindo amostras encaminhadas diretamente ao Laboratório de Virologia Molecular do Centro de Pesquisa em Virologia.

Este projeto foi encaminhado ao Comitê de Ética Médica do Hospital das Clínicas da FMRP e submetido à aprovação da Secretaria de Saúde de Ribeirão Preto. O termo de consentimento foi obtido para todos os indivíduos que participaram desta pesquisa.

\subsection{Extração do DNA}

A extração das amostras de DNA foi feita com o kit GenElute ${ }^{\text {TM }}$ Blood GenomicDNA (Sigma-Aldrich) de acordo com as recomendações do fabricante.

\subsection{Desenho dos primers}

Foram desenhados dois pares de primers, um cujo fragmento resultante da amplificação apresenta $150 \mathrm{pb}$ (par de primers A) e outro $1250 \mathrm{pb}$ (par de primers B), sendo que ambos incluíram os aminoácidos RGD (Arg-Gly-Asp) localizados no domínio homo B (tabela 1).

Tabela 1. Sequências dos primers desenhados.

\begin{tabular}{l|l|l} 
& \multicolumn{1}{|c|}{ Forward } & \multicolumn{1}{c}{ Reverse } \\
\hline Par de primers A & 5'-GGCGAGCCCAACCACATC-3' & 5'-GTGCTTGCTCTGTCCCTGC-3' \\
\hline Par de primers B & 5'-ACCTCAATGCCAACGACTG-3' & 5'-GCGGTGCCATAGAGTACGAG-3'
\end{tabular}




\subsection{Amplificação do domínio homo B por PCR em Tempo Real}

\subsubsection{Padronização da reação por PCR convencional}

Para padronizar a reação de PCR, a amplificação da região de interesse foi realizada inicialmente com o kit TopTaq Master Mix (QIAGEN, California, USA) de acordo com as recomendações do fabricante, utilizando o DNA de uma das amostras (20 ng/ $\mu \mathrm{l}$ ) e o par de primers B. A concentração inicial dos primers estava à $10 \mu \mathrm{M}$ e foram utilizadas três diferentes temperaturas de annealing: $55^{\circ} \mathrm{C}, 57^{\circ} \mathrm{C}$ e $60^{\circ} \mathrm{C}$. $\mathrm{O}$ produto de PCR foi aplicado com loading dye e o intercalante de DNA Gel Red em um gel de agarose $2 \%$, a $80 \mathrm{~V}$, por 1 hora. Após estabelecer as concentrações e temperaturas ideais, foi feita a PCR convencional de todas as amostras.

\subsubsection{Purificação do DNA a partir do gel de agarose}

As bandas de DNA foram recortadas do gel de agarose e purificadas com o kit Wizard® SV Gel and PCR Clean-up System (Promega), de acordo com as recomendações do fabricante.

\subsubsection{Padronização da reação de PCR em Tempo Real}

A reação de PCR em Tempo Real foi realizada com o kit MeltDoctor ${ }^{T M} H R M$ Master Mix, utilizando o par de primers A e o DNA purificado (item 4.4.2.). O volume final da reação foi padronizado para $10 \mu \mathrm{l}$, a concentração inicial dos primers estava à $5 \mu \mathrm{M}$ e o DNA à $20 \mathrm{ng} / \mu \mathrm{l}$. As temperaturas utilizadas na corrida no termociclador 7500 FAST Real Time PCR System (Applied Biosystems) seguiram as recomendações do fabricante. Após estabelecer as concentrações ideais, foi feita a PCR em Tempo Real de todas as amostras.

\subsubsection{Análise por High Resolution Melting (HRM)}

Ao final da reação de PCR em Tempo Real, todas as amostras foram analisadas com o software HRM (Life Technologies). Esse software gera todos os dados necessários para a análise da PCR em Tempo Real, como temperaturas de melting, genotipagem de todas as amostras, além de gerar os gráficos com as curvas das diferentes variantes. 


\subsection{Reação de sequenciamento do DNA}

Para cada amostra a ser sequenciada em microplaca de 96 poços, foram utilizados aproximadamente $100 \mathrm{ng}$ do DNA purificado (item 4.4.2.), 3,2 pmol de primers (primers B), $2 \mu \mathrm{l}$ de "Big Dye" (deoxinucleotídeos, dideoxinucleotídeos fluorescentes, enzima Taq DNA-Polimerase), $2 \mu$ de tampão "Big Dye" (200 mM Tris$\mathrm{HCl} \mathrm{pH} \mathrm{9,0} \mathrm{e} 5 \mathrm{mM}$ de Cloreto de Magnésio) e água milli-Q estéril, para completar o volume final de $10 \mu \mathrm{l}$. A termociclagem foi feita de acordo com as recomendações do fabricante. Após a amplificação, as amostras foram purificadas com o kit ExoSAP-IT PCR Product Cleanup (Affymetrix), de acordo com as recomendações do fabricante.

\subsubsection{Precipitação das amostras}

Em cada poço da placa de 96 poços, foi adicionado $1 \mu \mathrm{l}$ de EDTA a $125 \mathrm{mM}, 1$ $\mu \mathrm{l}$ de $\mathrm{NaOAc}$ a $3 \mathrm{M}$ (pH 4,8 a 5,2) e $40 \mu \mathrm{l}$ de etanol 100\% gelado. Após misturar bem com a pipeta, a placa foi incubada na geladeira por 30 minutos e centrifugada a 2250 g durante 40 minutos. Ao final dessa centrifugação, a placa foi invertida na pia para a remoção do etanol e centrifugada invertida em papel, por 1 minuto a $185 \mathrm{~g}$. Em seguida, foram adicionados $100 \mu \mathrm{l}$ de etanol $70 \%$, preparado no momento do uso, e a placa foi novamente centrifugada a $2250 \mathrm{~g}$ por 20 minutos. Novamente, a placa foi invertida na pia para a remoção do etanol e centrifugada invertida em papel, por 1 minuto a $185 \mathrm{~g}$. Em cada poço, foram adicionados $10 \mu \mathrm{l}$ de formamida HiDye. Antes das amostras serem sequenciadas, elas foram desnaturadas em um termociclador por 5 minutos a $95^{\circ} \mathrm{C}$ e mantidas no mínimo por 3 minutos a $4^{\circ} \mathrm{C}$.

\subsection{Análise das sequências genômicas}

As sequências nucleotídicas obtidas foram editadas para a remoção das regiões intrônicas utilizando o programa DNAStar Lasergene e foram alinhadas com uma sequência de RNA mensageiro do gene da furina, disponível no GenBank (número de acesso: X17094.1), utilizando o programa BioEdit Sequence Alignment Editor. 


\section{RESULTADOS}

\subsection{Padronização da reação por PCR convencional}

A reação de $\mathrm{PCR}$ convencional foi realizada inicialmente com uma amostra de DNA (figura 7. A.) utilizando o par de primers $B$ e, após a padronização, a reação de PCR foi realizada com todas as amostras. A figura 7 mostra que todas as amostras testadas foram amplificadas na região de interesse, sem a formação de dímeros.
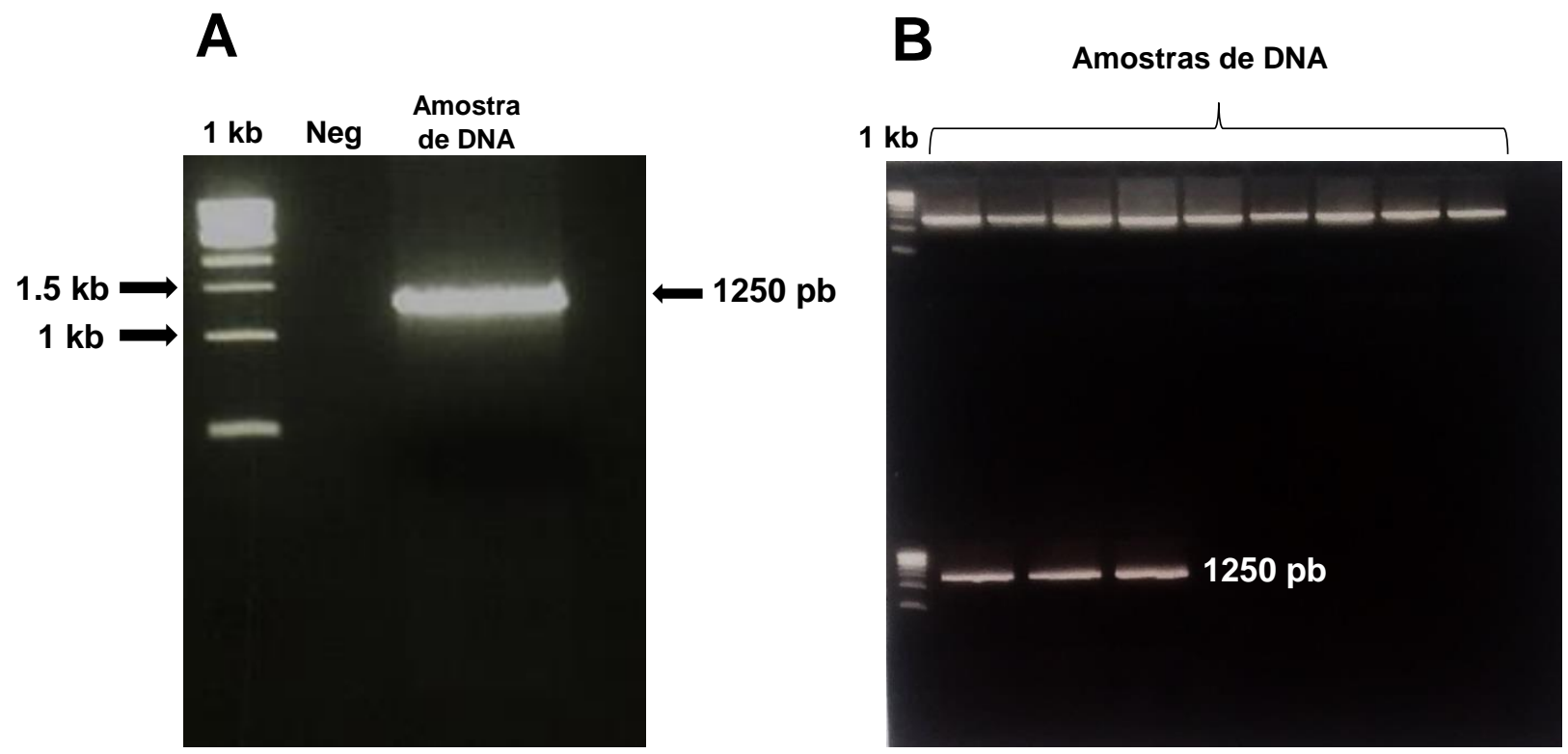

Figura 7. Gel de eletroforese mostrando parte da região do domínio homo B amplificada sob a temperatura de $60^{\circ} \mathrm{C}$. A. Na ordem: marcador de $1 \mathrm{~kb}$, controle negativo (neg) e amostra de DNA. B. $\mathrm{Na}$ ordem: marcador de $1 \mathrm{~kb}$ e algumas amostras de DNA de diferentes pacientes.

\subsection{Purificação do DNA a partir do gel de agarose}

Todas as bandas de $1250 \mathrm{pb}$ foram purificadas do gel de agarose e o DNA purificado foi utilizado como molde para a reação de PCR em Tempo Real utilizando o par de primers A. Para confirmar a presença do fragmento de $150 \mathrm{pb}$, foi realizada a PCR convencional utilizando o DNA purificado de algumas amostras e o par de primers $\mathrm{A}$. $\mathrm{O}$ resultado do gel de eletroforese é mostrado na figura 8. 


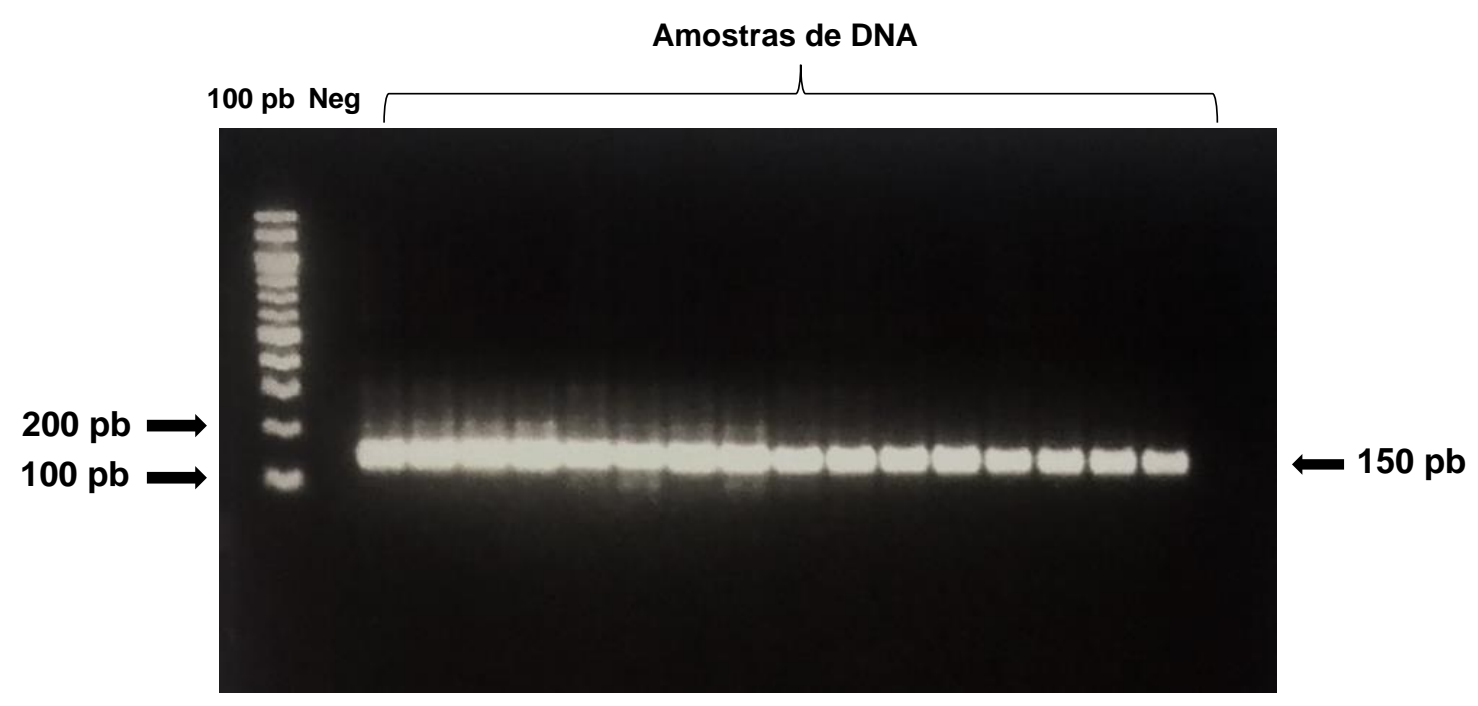

Figura 8. Gel de eletroforese mostrando o fragmento de $150 \mathrm{pb}$ obtido após a realização de uma segunda PCR convencional. Na ordem: marcador de 100 pb, controle negativo (neg) e amostras de DNA purificado de diferentes pacientes.

\subsection{PCR em Tempo Real e análise por HRM}

Após a realização da PCR em Tempo Real de todas as amostras foi feita a análise por HRM. A figura 9 mostra os gráficos obtidos por esse software para as amostras dos grupos "Dengue" e "Dengue grave". A figura 9A mostra que todas as amostras desses dois grupos representam apenas uma variante, ou seja, não foi detectada nenhuma mutação. Já a figura 9B mostra a presença de apenas um pico bem definido da temperatura de melting, o que significa que todas as amostras representam a mesma variante

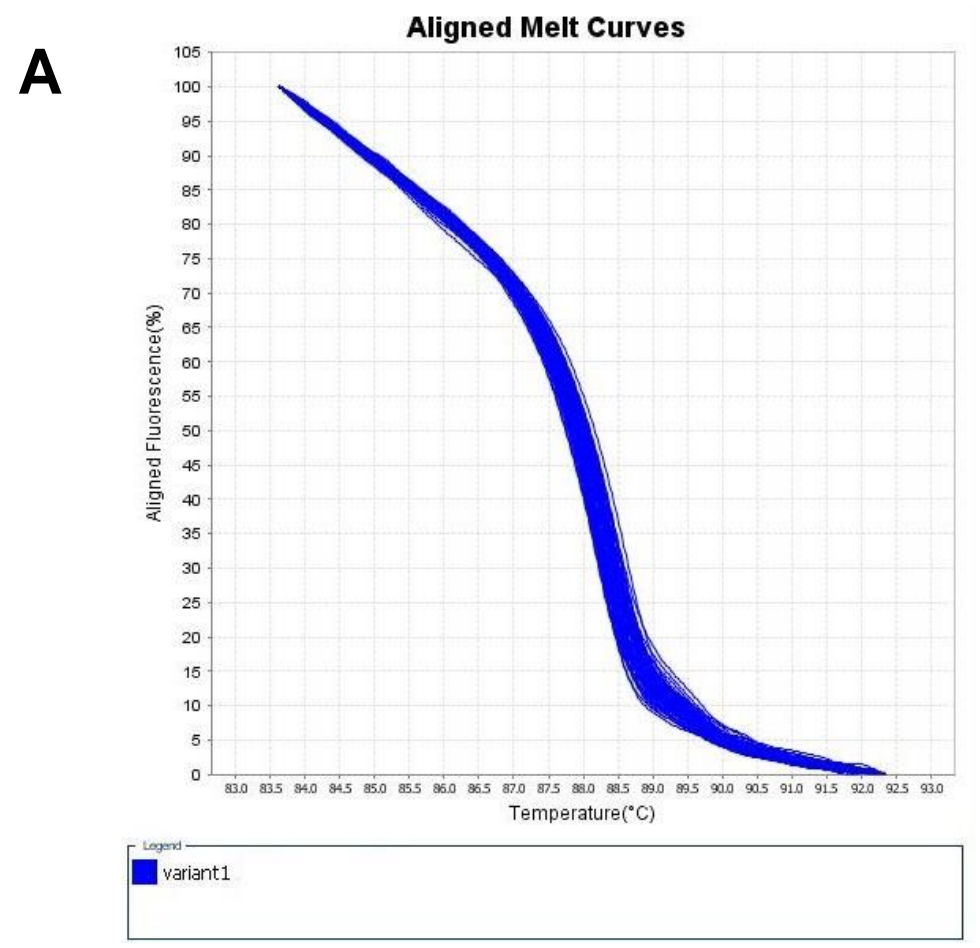




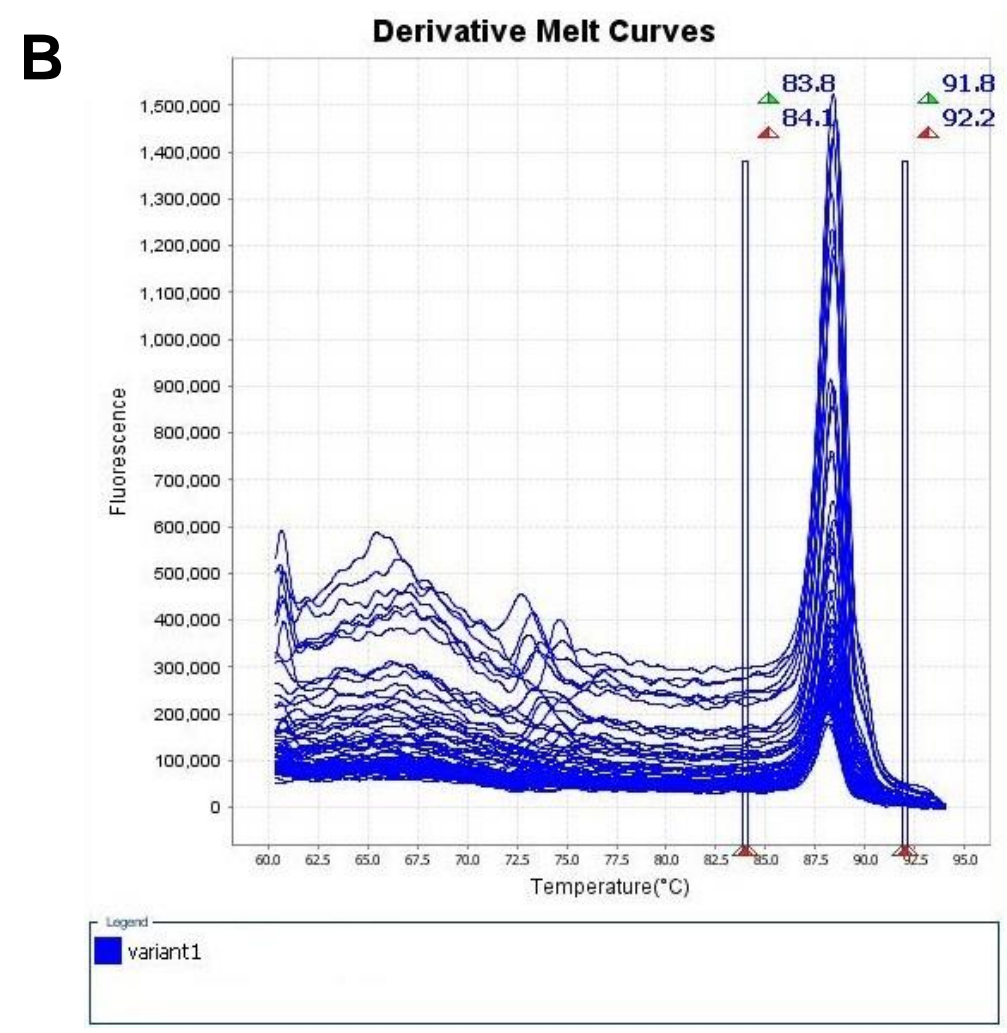

Figura 9. Amostras dos grupos "Dengue" e "Dengue grave" analisadas por HRM. A. Aligned melt curves. B. Derivative melt curves.

A figura 10 mostra os gráficos obtidos pelo HRM de algumas amostras do grupo "Controle". Diferente dos outros grupos, das 211 amostras, 57 foram classificadas como sendo diferentes variantes, ou seja, que apresentam alguma mutação na região amplificada.

Comparando a figura 10A com a 9A é possível perceber que as curvas não se sobrepõem como as mostradas em azul, o que representa as diferenças nas temperaturas de melting das amostras do grupo "Controle", classificadas como diferentes variantes. Apesar de ser nítida a sobreposição dos picos de temperatura na figura 9B, o que condiz com a classificação de todas as amostras como uma única variante, a figura 10B não evidencia as diferenças de temperatura, o que é mostrado apenas pela diferença de cor dos picos. 


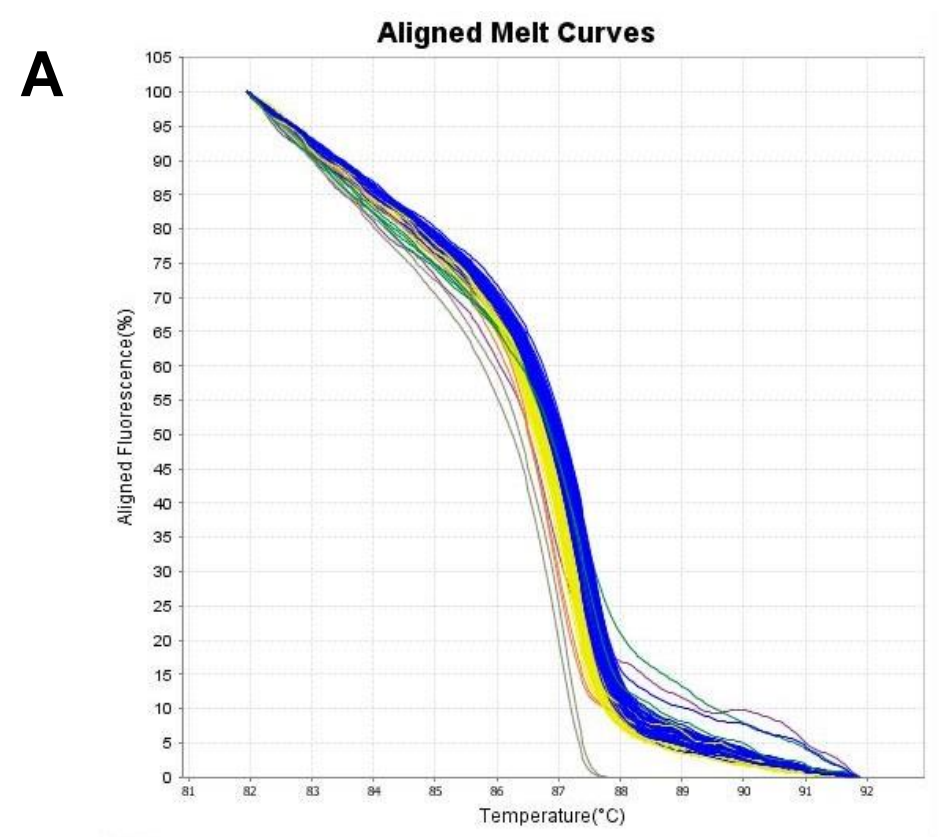

variant1 $\square$ variant2 $\square$ variant3 $\square$ variant4 $\square$ variant5 $\square$ variant6

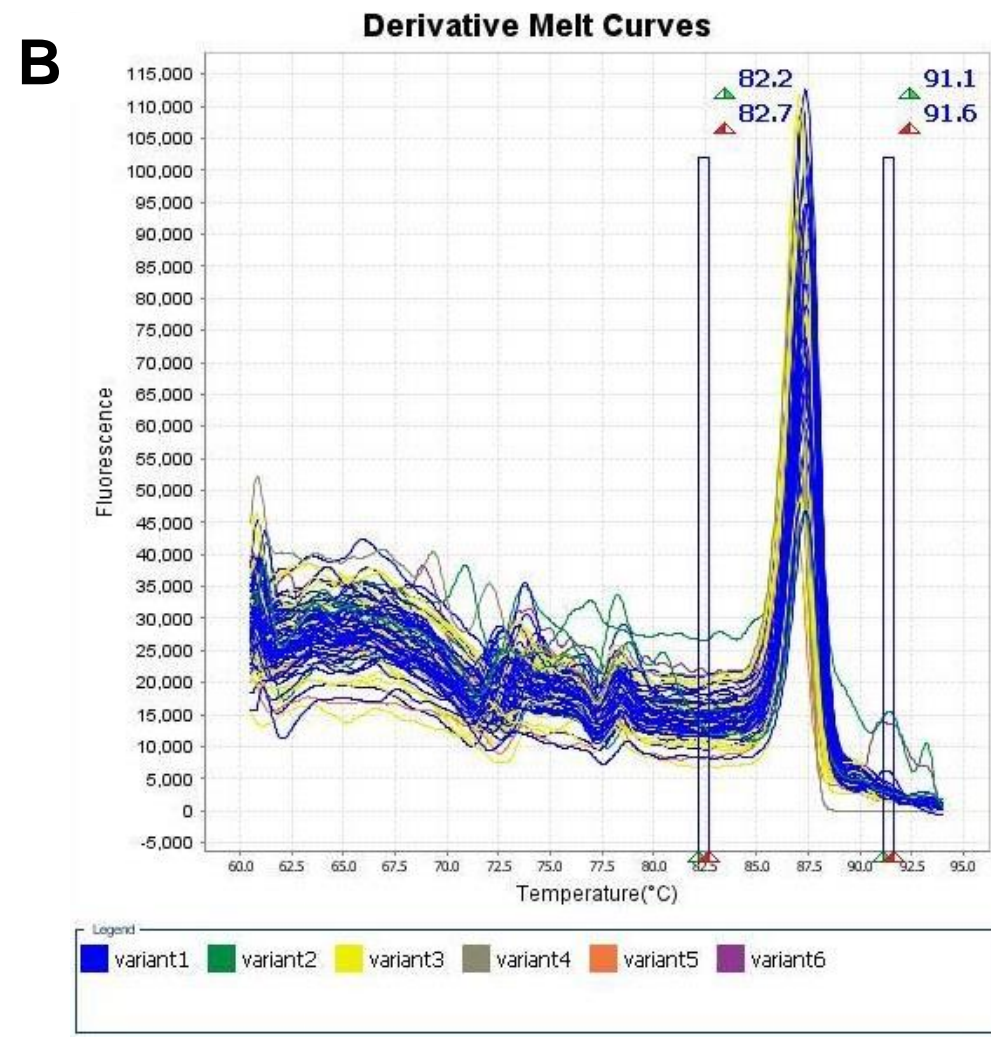

Figura 10. Amostras do grupo "Controle" analisadas por HRM. A. Aligned melt curves. B. Derivative melt curves. 


\subsection{Sequenciamento das amostras selecionadas por HRM}

As 57 amostras classificadas como diferentes variantes pelo HRM foram submetidas ao sequenciamento, mas 27 não atingiram a qualidade necessária para essa análise e 30 foram sequenciadas corretamente. A figura 11 mostra o alinhamento da sequência de RNA mensageiro da furina ( $1^{\text {a }}$ sequência da figura) com as 30 sequências obtidas, com destaque para a região nucleotídica referente aos aminoácidos RGD. O alinhamento mostrou que na região do sítio catalítico da furina, apesar do HRM ter apontado a presença de mutações, não há nenhuma mutação na região de interesse, havendo o alinhamento completo da sequência nucleotídica das amostras com a sequência do RNA mensageiro original do gene da furina.

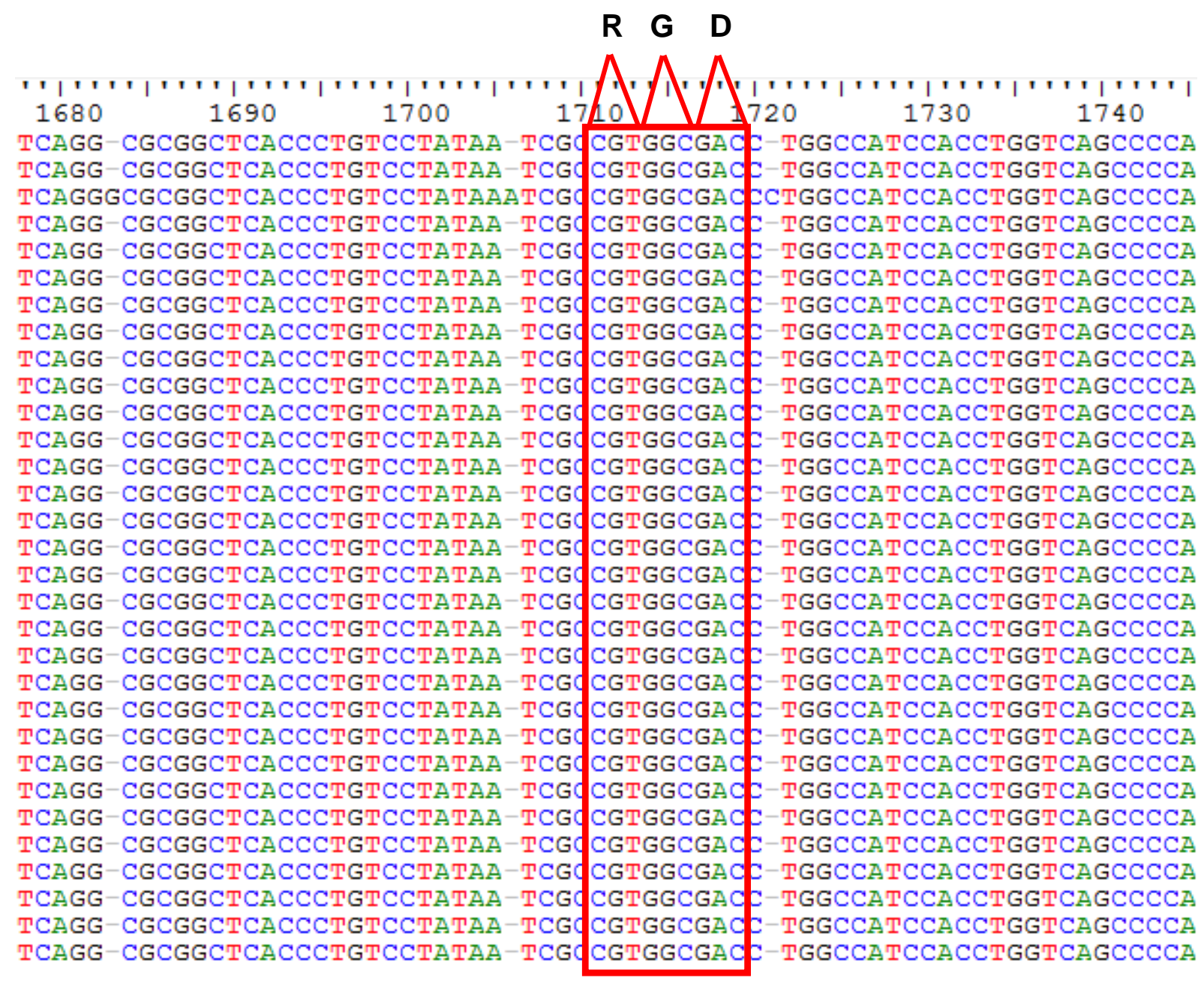

Figura 11. Alinhamento das amostras do grupo "Controle" com a sequência de RNA mensageiro da furina. Destaque da sequência de nucleotídeos referente aos aminoácidos "RGD". 
Apesar da região dos aminoácidos "RGD" não apresentar nenhuma mutação em nenhuma das amostras analisadas, a $3^{\underline{a}}$ sequência da figura 11 apresentou 3 inserções: nucleotídeos $\mathrm{G}, \mathrm{A}$ e C. Porém, a análise do cromatograma revelou que a qualidade do sequenciamento nessa região dessa determinada amostra não estava favorável, como pode ser visto na figura 12.

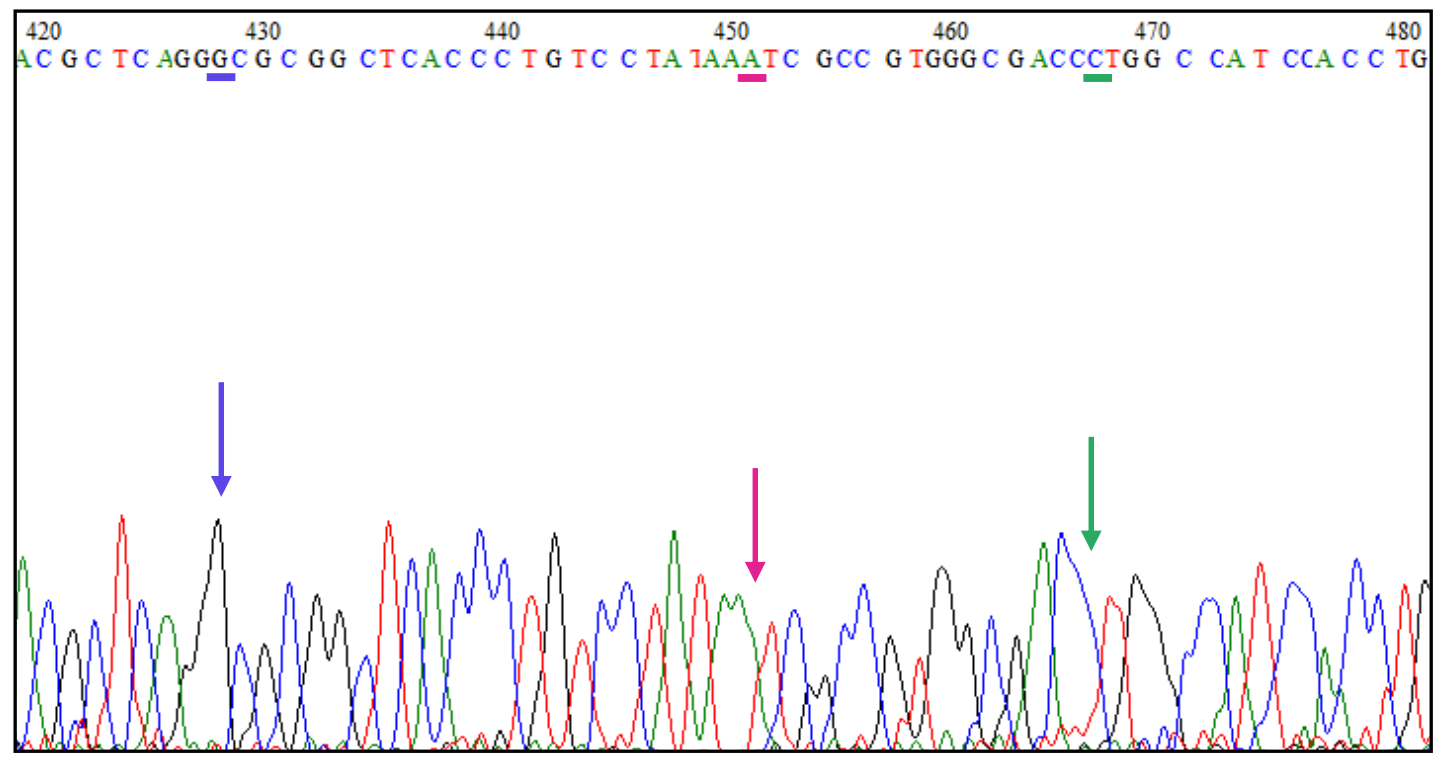

Figura 12. Cromatograma mostrando as inserções detectadas pelo sequenciamento. As setas indicam o pico referente à cada inserção. Azul: inserção do nucleotídeo G. Rosa: inserção do nucleotídeo A. Verde: inserção do nucleotídeo C.

\subsubsection{Sequenciamento das amostras dos grupos "Dengue" e "Dengue grave"}

Como as amostras do grupo "Controle" selecionadas pelo HRM não apresentaram nenhum tipo de mutação, por sequenciamento, na região de interesse, as amostras dos outros dois grupos, grupo "Dengue" e "Dengue grave", também foram sequenciadas, apesar de não terem sido classificadas como diferentes variantes. Da mesma forma, nenhuma delas mostrou a presença de qualquer mutação na região correspondente à sequência dos aminoácidos RGD, como mostra a figura 13. 


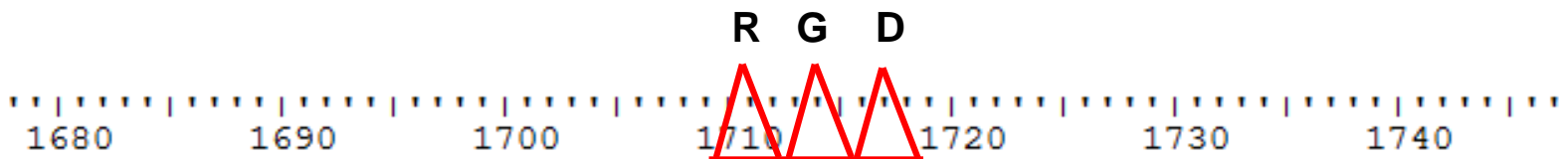

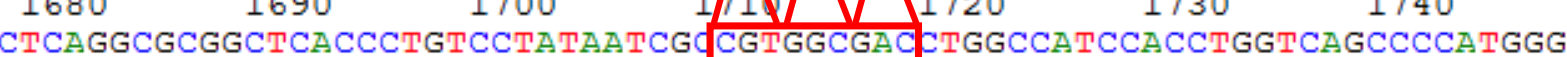
СTCAGGCGCGGCTCACCCTGTCСтATAATCGCCGTGGCGACETGGCCATCCACСTGGTCAGCCCCATGGG CTCAGGCGCGGCTCACCCTGTCCTATAATCGCCGTGGCGACETGGCCATCCACCTGGTCAGCCCCATGGG CTCAGGCGCGGCTCACCCTGTCCTATAATCGCCGTGGCGAC TTGGCCATCCACCTGGTCAGCCCCATGGG CTCAGGCGCGGCTCACCCTGTCCTATAATCGCCGTGGCGACETGGCCATCCACCTGGTCAGCCCCATGGG СTCAGGCGCGGCTCACCCTGTCCTATAATCGCGTGGCGACCTGGCCATCCACCTGGTCAGCCCCATGGG CTCAGGCGCGGCTCACCCTGTCCTATAATCGCCGTGGCGACETGGCCATCCACCTGGTCAGCCCCATGGG CTCAGGCGCGGCTCACCCTGTCCTATAATCGCGTGGCGACTTGGCATCCACCTGGTCAGCCCCATGGG СTCAGGCGCGGCTCACCCTGTCCTATAATCGCCGTGGCGACETGGCCATCCACCTGGTCAGCCCCATGGG СTCAGGCGCGGCTCACCCTGTCCTATAATCGCGTGGCGAC TTGCCATCCACCTGGTCAGCCCCATGGG СTCAGGCGCGGCTCACCCTGTCСтAтAATCGCCGTGGCGACCTGGCCATCCACCTGGTCAGCCCCATGGG СTCAGGCGCGGCTCACCCTGTCСтATAATCGACGTGGCGACCTGGCCATCCACCTGGTCAGCCCCATGGG СTCAGGCGCGGCTCACСCTGTCСтAтAATCGCCGTGGCGACETGGCCATCCACСTGGTCARCCCCATGGG CTCAGGCGCGGCTCACCCTGTCCTATAATCGCCGTGGCGACETGGCCATCCACCTGGTCAGCCCCATGGG СTCAGGCGCGGCTCACССTGTCСтAтAATCGCCGTGGCGACCTGGCCATCCACСTGGTCAGCCCCATGGG CTCAGGCGCGGCTCACCCTGTCCTATAATCGđCGTGGCGACETGGCCATCCACCTGGTCAGCCCCATGGG CTCAGGCGCGGCTCACCCTGTCCTATAATCGCCGTGGCGAC TTGGCCATCCACCTGGTCAGCCCCATGGG CTCAGGCGCGGCTCACCCTGTCCTATAATCGđCGTGGCGACETGGCCATCCACCTGGTCAGCCCCATGGG CTCAGGCGCGGCTCACCCTGTCСTATAATCGCCGTGGCGAC TTGCCATCCACCTGGTCAGCCCCATGGG CTCAGGCGCGGCTCACCCTGTCCTATAATCG_CGTGGCGACETGGCCATCCACCTGGTCAGCCCCATGGG CTCAGGCGCGGCTCACCCTGTCСтATAATCGCCGTGGCGACETGGCCATCCACCTGGTCAGCCCCATGGG СтCAGGCGCGGCTCACССTGTCСтАтАATCGCCGTGGCGACCTGGCCATCCACСTGGTCAGCCCCATGGG СTCAGGCGCGGCTCACСCTGTCСтAтAATCGCCGTGGCGACCTGGCCATCCACСTGGTCAGCCCCATGGG CTCAGGCGCGGCTCACCCTGTCCTATAATCGCCGTGGCGACETGGCCATCCACCTGGTCAGCCCCATGGG СTCAGGCGCGGCTCACCCTGTCCTATAATCGCCGTGGCGACCTGGCCATCCACCTGGTCAGCCCCATGGG CTCAGGCGCGGCTCACCCTGTCCTATAATCGCCGTGGCGACETGGCCATCCACCTGGTCAGCCCCATGGG СTCAGGCGCGGCTCACССTGTCСтAтAATCGCCGTGGCGACTTGCCATCCACСTGGTCAGCCCCATGGG СTCAGGCGCGGCTCACСCTGTCCTATAдTCGCCGTGGCGACETGGCCATCCACCTGGTCAGCCCCATGGG СтCAGGCGCGGCTCACCCTGTCСтAтAАTCGCCGTGGCGACPTGGCCATCCACСTGGTCAGCCCCATGGG CTCAGGCGCGGCTCACCCTGTCСTATAATCGCCGTGGCGACETGGCCATCCACCTGGTCAGCCCCATGGG CTCAGGCGCGGCTCACCCTGTCCTATAATCGdCGTGGCGA CTGGCCATCCACCTGGTCAGCCCCATGGG CTCAGGCGCGGCTCACCCTGTCCTATAATCGđCGTGGCGA CTGGCCATCCACCTGGTCAGCCCCATGGG CTCAGGCGCGGCTCACCCTGTCCTATAATCGCCGTGGCGAC CTGGCCATCCACCTGGTCAGCCCCATGGG
\end{abstract}

Figura 13. Alinhamento das amostras dos grupos "Dengue" e "Dengue grave" com a sequência de RNA mensageiro da furina. Destaque da sequência de nucleotídeos referente aos aminoácidos "RGD".

\title{
5.4.2. Análise de outras mutações por sequenciamento
}

Apesar do fragmento analisado por HRM incluir, dentre as mutações descritas na literatura, apenas a região dos aminoácidos RGD, o sequenciamento incluiu uma região maior, abrangendo o aminoácido que é mutado (Trp para Arg) nas células LoVo (células de adenocarcinoma humano) na posição 547 da sequência de aminoácidos do domínio homo B. Essa análise foi importante para verificar se essa mutação seria, de alguma forma, responsável pelas diferentes manifestações da dengue, já que as células LoVo não produzem furina ativa, de tal forma que ela não é capaz de deixar o retículo endoplasmático das células (Takahashi et al, 1995). Da mesma maneira, nenhuma mutação foi detectada nessa sequência, como pode ser visto nas figuras 14A e 14B. 
GTGCGGAAGACCGTGACCGCGTGC TGGGCGAGCCCAACCACATCACTCGG GTGCGGAA GACCGTGACCGCGTGC TGGGCGA GCCCAACCACATCACTCGG GTGCGGAA GACCGTGACCGCGTGC TGG GCGA GCCCAACCACATCACTCGG GTGCGGAAGACCGTGACCGCGTGC TGG GCGAGCCCAACCACATCACTCGG GTGCGGAA GACCGTGACCGCGTGC TGG GCGA GCCCAACCACATCACTCGG GTGCGGAAGACCGTGACCGCGTGC TGGGCGAGCCCAACCACATCACTCGG GTGCGGAAGACCGTGACCGCGTGC TGGGCGAGCCCAACCACATCACTCGG GTGCGGAAGACCGTGACCGCGTGC TGGGCGAGCCCAACCACATCACTCGG GTGCGGAAGACCGTGACCGCGTGCDTGGGCGAGCCCAACCACATCACTCGG GTGCGGAAGACCGTGACCGCGTGC TGGGCGAGCCCAACCACATCACTCGG GTGCGGAAGACCGTGACCGCGTGCDTGGGCGAGCCCAACCACATCACTCGG GTGCGGAAGACCGTGACCGCGTGC TGG GCGAGCCCAACCACATCACTCGG GTGCGGAAGACCGTGACCGCGTGC TGGGCGAGCCCAACCACATCACTCGG GTGCGGAA GACCGTGACCGCGTGC TGG GCGA GCCCAACCACATCACTCGG GTGCGGAAGACCGTGACCGCGTGC TGGGCGAGCCCAACCACATCACTCGG GTGCGGAA GACCGTGACCGCGTGC TGG GCGA GCCCAACCACATCACTCGG GTGCGGAAGACCGTGACCGCGTGC TGG GCGAGCCCAACCACATCACTCGG GTGCGGAA GACCGTGACCGCGTGC TGG GCGA GCCCAACCACATCACTCGG GTGCGGAAGACCGTGACCGCGTGC TGGGCGAGCCCAACCACATCACTCGG GTGCGGAA GACCGTGACCGCGTGC TGG GCGA GCCCAACCACATCACTCGG GTGCGGAAGACCGTGACCGCGTGC TGGGCGAGCCCAACCACATCACTCGG GTGCGGAA GACCGTGACCGCGTGC TGG GCGA GCCCAACCACATCACTCGG GTGCGGAAGACCGTGACCGCGTGCDTGGGCGAGCCCAACCACATCACTCGG GTGCGGAAGACCGTGACCGCGTGC TGGGCGAGCCCAACCACATCACTCGG GTGCGGAAGACCGTGACCGCGTGC TGGGCGAGCCCAACCACATCACTCGG GTGCGGAAGACCGTGACCGCGTGCDTGGGCGAGCCCAACCACATCACTCGG GTGCGGAA GACCGTGACCGCGTGC TGG GCGAGCCCAACCACATCACTCGG GTGCGGAAGACCGTGACCGCGTGC TGGGCGAGCCCAACCACATCACTCGG GTGCGGAAGACCGTGACCGCGTGC TGG GCGAGCCCAACCACATCACTCGG GTGCGGAAGACCGTGACCGCGTGC TGGGCGAGCCCAACCACATCACTCGG GTGCGGAA GACCGTGACCGCGTGC TGG GCGAGCCCAACCACATCACTCGG

\section{B}

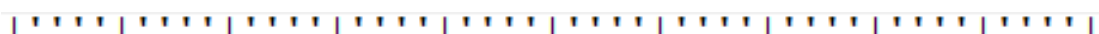

$$
\begin{aligned}
& 1620
\end{aligned}
$$$$
1630
$$

1640

1650

1660

AGGTGCGGAAGACCGTGACCGCGTGC $₫$ TGGGCGAGCCCAACCACATCACTC AGGTGCGGAAGACCGTGACCGCGTGC TGGGCGAGCCCAACCACATCACTC AGGTGCGGAAGACCGTGACCGCGTGC TGGGCGA GCCCAACCACATCACTC AGGTGCGGAAGACCGTGACCGCGTGC TGG GCGAGCCCAACCACATCACTC AGGTGCGGAA GACCGTGACCGCGTGC TGG GCGAGCCCAACCACATCACTC AGGTGCGGAAGACCGTGACCGCGTGC TGGGCGAGCCCAACCACATCACTC AGGTGCGGAAGACCGTGACCGCGTGC TGG GCGA GCCCAACCACATCACTC AGGTGCGGAAGACCGTGACCGCGTGC TGGGCGAGCCCAACCACATCACTC AGGTGCGGAAGACCGTGACCGCGTGC TGGGCGAGCCCAACCACATCACTC AGGTGCGGAAGACCGTGACCGCGTGC TGGGCGAGCCCAACCACATCACTC AGGTGCGGAAGACCGTGACCGCGTGC TGGGCGAGCCCAACCACATCACTC AGGTGCGGAAGACCGTGACCGCGTGC TGGGCGAGCCCAACCACATCACTC AGGTGCGGAAGACCGTGACCGCGTGC TGGGCGAGCCCAACCACATCACTC AGGTGCGGAAGACCGTGACCGCGTGC TGGGCGAGCCCAACCACATCACTC AGGTGCGGAAGACCGTGACCGCGTGC TGGGCGAGCCCAACCACATCACTC AGGTGCGGAAGACCGTGACCGCGTGC TGG GCGA GCCCAACCACATCACTC AGGTGCGGAAGACCGTGACCGCGTGC TGGGCGAGCCCAACCACATCACTC AGGTGCGGAA GACCGTGACCGCGTGC TGG GCGA GCCCAACCACATCACTC AGGTGCGGAAGACCGTGACCGCGTGC TGG GCGAGCCCAACCACATCACTC AGGTGCGGAAGACCGTGACCGCGTGC TGG GCGA GCCCAACCACATCACTC AGGTGCGGAAGACCGTGACCGCGTGC TGG GCGAGCCCAACCACATCACTC AGGTGCGGAA GACCGTGACCGCGTGC TGG GCGA GCCCAACCACATCACTC AGGTGCGGAAGAMCGTGACCGCGTGC TGGGCGARCCCAACCACATCACTC AGGTGCGGAAGACCGTGACCGCGTGC TGGGCGAGCCCAACCACATCACTC AGGTGCGGAAGACCGTGACCGCGTGC TGGGCGAGCCCAACCACATCACTC AGGTGCGGAA GACCGTGACCGCGTGC TGG GCGAGCCCAACCACATCACTC AGGTGCGGAAGACCGTGACCGCGTGC TGGGCGAGCCCAACCACATCACTC AGGTGCGGAAGACCGTGACCGCGTGC TGGGCGAGCCCAACCACATCACTC AGGTGCGGAAGACCGTGACCGCGTGC TGGGCGAGCCCAACCACATCACTC AGGTGCGGAAGACCGTGACCGCGTGC TGGGCGAGCCCAACCACATCACTC AGGTGCGGAAGACCGTGACCGCGTGC TGGGCGAGCCCAACCACATCACTC AGGTGCGGAAGACCGTGACCGCGTGC TGG GCGAGCCCAACCACATCACTC AGGTGCGGAA GACCGTGACCGCGTGC TGGGCGA GCCCAACCACATCACTC

Figura 14. Sequências destacadas referentes ao aminoácido triptofano (Trp). A. Amostras do grupo "Controle". B. Amostras dos grupos "Dengue" e "Dengue grave". 


\subsection{Análise da qualidade da genotipagem pelo valor do Silhouette Score}

A análise da qualidade da genotipagem foi realizada por meio do valor obtido pelo Silhouette Score. Das 57 amostras classificadas como diferentes variantes pelo HRM, apenas 3 tiveram o valor do Silhouette Score abaixo de 0.8 (tabela 2), sendo o valor ideal maior ou igual a 0.8 . Isso indica que, segundo esse valor, a classificação da grande maioria das amostras como mutantes foi correta, porém o sequenciamento mostrou que todas as amostras alinharam perfeitamente com a sequência do RNA mensageiro da furina, sem a presença de qualquer mutação.

Tabela 2. Valor do Silhouette Score das amostras classificadas como mutantes pelo HRM. Em vermelho estão as amostras que obtiveram valor menor que 0.8 .

\begin{tabular}{|c|c|}
\hline Amostra & Silhouette Score \\
\hline 1 & 0.913 \\
\hline 2 & 0.750 \\
\hline 3 & 0.947 \\
\hline 4 & 0.818 \\
\hline 5 & 0.905 \\
\hline 6 & 0.801 \\
\hline 7 & 0.981 \\
\hline 8 & 0.852 \\
\hline 9 & 0.849 \\
\hline 10 & 0.987 \\
\hline 11 & 0.919 \\
\hline 12 & 0.904 \\
\hline 13 & 0.836 \\
\hline 14 & 0.869 \\
\hline 15 & 0.951 \\
\hline 16 & 0.978 \\
\hline 17 & 0.950 \\
\hline 18 & 0.916 \\
\hline 19 & 0.809 \\
\hline 20 & 0.813 \\
\hline 21 & 0.968 \\
\hline 22 & 0.946 \\
\hline 23 & 0.865 \\
\hline 24 & 0.957 \\
\hline 25 & 0.980 \\
\hline
\end{tabular}




\begin{tabular}{|c|c|}
\hline 26 & 0.959 \\
\hline 27 & 0.629 \\
\hline 28 & 0.790 \\
\hline 29 & 0.900 \\
\hline 30 & 0.867 \\
\hline 31 & 0.884 \\
\hline 32 & 0.894 \\
\hline 33 & 0.847 \\
\hline 34 & 0.934 \\
\hline 35 & 0.895 \\
\hline 36 & 0.922 \\
\hline 37 & 0.942 \\
\hline 38 & 0.953 \\
\hline 39 & 0.947 \\
\hline 40 & 0.889 \\
\hline 41 & 0.941 \\
\hline 42 & 0.944 \\
\hline 43 & 0.907 \\
\hline 44 & 0.950 \\
\hline 45 & 0.912 \\
\hline 46 & 0.952 \\
\hline 47 & 0.922 \\
\hline 48 & 0.932 \\
\hline 49 & 0.871 \\
\hline 50 & 0.899 \\
\hline 51 & 0.942 \\
\hline 52 & 0.820 \\
\hline 53 & 0.952 \\
\hline 54 & 0.960 \\
\hline 55 & 0.958 \\
\hline 56 & 0.948 \\
\hline 57 & 0.841 \\
\hline
\end{tabular}




\section{DISCUSSÃO}

A dengue é uma doença que acomete cada vez mais a população mundial, sendo a prevenção e o controle do vetor as únicas formas de diminuir os casos de infecção (Horstick et al, 2015). Existem alguns fatores que justificam o aumento anual do número de casos, como o crescimento populacional associado à urbanização mal planejada, principalmente nos países tropicais em desenvolvimento, habitações precárias e problemas nos sistemas de água e esgoto (Gubler, 1998). Como resultado, ocorrem cerca de 390 milhões de infecções pelos vírus dengue anualmente em todo o mundo (Bhatt et al, 2013). Por isso, é muito importante o entendimento dessa doença, bem como o estudo de fatores do hospedeiro, no caso o ser humano, que podem estar relacionados com a manifestação clínica da dengue.

Sabe-se que a endoprotease furina é extremamente importante no ciclo de replicação dos vírus dengue, uma vez que ela cliva a proteína viral prM em proteína M madura, sendo esse processo essencial para a maturação viral e liberação dos vírus infecciosos da célula (Pierson and Diamond, 2012; Halstead, 2003). Fatores genéticos estão relacionados diretamente com a atividade catalítica dessa endoprotease. Alguns estudos mostram que a presença de mutações em algumas regiões do gene da furina podem levar à modificação e até mesmo à perda de sua atividade catalítica. Nesse caso, a maturação das partículas virais pode ser prejudicada, já que a proteína prM não será clivada e, consequentemente, o vírus permanecerá imaturo (Lee et al, 2013).

Takahashi e colaboradores (1995) realizaram um estudo que indica a importância do domínio homo $\mathrm{B}$, domínio do gene da furina relacionado com a sua atividade catalítica. Nesse trabalho, eles mostraram que células de adenocarcinoma humano (LoVo cells) apresentam uma mutação de apenas um aminoácido por outro, no caso o triptofano (Trp) pela arginina ( $\operatorname{Arg}$ ) na posição 547 da sequência de aminoácidos do domínio homo $\mathrm{B}$, e essa alteração leva à perda completa da ativação autocatalítica da furina, de tal maneira que a forma mutante não é capaz de deixar o retículo endoplasmático.

Outro estudo de grande importância foi feito por Zybert e colaboradores (2008). Eles produziram partículas virais imaturas de DENV-2 em células LoVo, que não produzem a endoprotease furina, e compararam-na com a produção de partículas virais em células de mosquito (C6/36), as quais expressam a furina normalmente. 
Como resultado, foi observado que o poder de infecção das partículas imaturas produzidas pela linhagem de células de adenocarcinoma humano era significativamente menor que o poder de infecção das partículas maduras produzidas pelas células de mosquito. Além disso, trataram in vitro as partículas virais imaturas com furina exógena para verificar se a infectividade dos vírus podia ser recuperada. O resultado desse trabalho mostrou que, após o tratamento com furina, a infectividade aumentou drasticamente, demonstrando que a perda do poder de infecção pelo vírus imaturo foi devido à ausência da clivagem da proteína prM em proteína $M$ pela furina.

Já o trabalho desenvolvido por Hatsuzawa e colaboradores (Hatsuzawa et al, 1992) foi essencial para demonstrar a importância do domínio homo B para a furina. Nesse trabalho, eles inseriram stop códons em diversas regiões do gene da furina e cada forma mutante foi co-expressa com a pró-renina, um substrato que também é clivado pela endoprotease. $O$ objetivo desse experimento foi mostrar se a perda de uma determinada região da furina inativa sua função, ou seja, se a pró-renina deixa de ser clivada.

Para isso, foi feita, inicialmente, uma mutação que levou à perda da região transmembrana da furina e como resultado eles viram que ela manteve a sua atividade, ou seja, a pró-renina foi clivada. Em seguida, foi feita uma outra mutação que levou à perda da região transmembrana e da região rica em cisteína. Da mesma forma, a furina manteve a sua atividade. Porém, quando a mutação foi inserida no interior do domínio homo $\mathrm{B}$, a furina perdeu a sua atividade e a pró-renina deixou de ser clivada, o que comprova a importância desse domínio (Hatsuzawa et al, 1992).

A furina faz parte da família das pró-proteínas convertases, endoproteases responsáveis pela conversão de precursores de proteínas em suas formas biologicamente ativas, por meio da clivagem de um sítio marcado por uma determinada sequência de aminoácidos. Juntamente à ela, outras seis endoproteases constituem essa família, sendo elas PC1, PC2, PACE4, PC4, PC5 e PC7 (Nakayama, 1997). Os aminoácidos RGD são conservados em todas elas, com exceção de PC7 (Lusson et al, 1997), e por isso eles são alvos de estudo para o entendimento da função do domínio homo B.

Lusson e colaboradores (Lusson et al, 1997) demonstraram que o processamento dessas endoproteases no interior do retículo endoplasmático fica comprometido quando são feitas mutações nesses aminoácidos. Sabe-se que a 
clivagem dos zimógenos, precursores enzimáticos inativos, é sensível a mutações ou deleções no domínio homo B (Zhong et al, 1996).

Assim sendo, o presente trabalho buscou analisar a presença de possíveis mutações nessa sequência conservada, utilizando a análise por High Resolution Melting. Essa técnica tem sido utilizada principalmente para estudos de doenças genéticas humanas (Taylor, 2009) e grande parte dos trabalhos comprova a alta sensibilidade do HRM na detecção de heterozigotos, sendo que substituições, inserções e deleções podem ser detectadas por esse método (Dobrowolski et al, 2005; Lonie et al, 2006; Nomoto et al, 2006).

Num trabalho comparativo realizado por Ihle e colaboradores (Ihle et al, 2014), tanto o HRM como o sequenciamento de Sanger foram capazes de detectar mutações raras no gene BRAF (proto-oncogene B-Raf) com 100\% de especificidade. Porém, vale ressaltar que o HRM é apenas um método de screening, não sendo possível verificar o tipo de mutação detectada, sendo, para isso, inevitável a utilização do sequenciamento (Jancik et al, 2012).

No presente trabalho, amplicons de 150 pb foram analisados por HRM com a intenção de identificar a presença de mutações na região dos aminoácidos RGD do domínio homo B da endoprotease furina. Entretanto, apesar de muitas amostras terem sido classificadas pelo HRM como sendo diferentes variantes, ou seja, que apresentam mutação na região estudada, o sequenciamento mostrou que nenhuma delas apresentava qualquer tipo de mutação. Uma possível explicação para isso é a utilização de diferentes métodos para a extração do DNA das amostras. A maioria das amostras dos grupos "Dengue" e "Dengue grave" já estavam previamente extraídas e armazenadas, sendo apenas descongeladas para a sua utilização nesse trabalho.

Já as amostras do grupo "Controle" foram extraídas com o kit GenElute ${ }^{\text {TM }}$ Blood GenomicDNA (Sigma-Aldrich), o qual pode apresentar diferença nas concentrações de sal dos buffers quando comparado àqueles do kit utilizado anteriormente para a extração das outras amostras. Isso foi visto em alguns trabalhos, nos quais amostras extraídas em diferentes laboratórios, utilizando diferentes buffers, produziram variações nas curvas de melting (Seipp et al, 2007; Leener et al, 2008). Além disso, a qualidade das amostras também pode variar. A maioria das amostras do grupo "Controle" foi obtida na Unidade de Emergência (UE) do Hospital das Clínicas de Ribeirão Preto (HCRP) e, por isso, o seu armazenamento após a coleta não foi monitorado. 
A soma de todos os resultados obtidos mostrou que a análise da região de estudo desse trabalho não é ideal quando feita por HRM e sim, por sequenciamento. Considerando apenas os resultados obtidos com esta técnica, é possível dizer que as manifestações mais graves da dengue não estão relacionadas com a presença de mutações no domínio homo $B$ do gene da furina, região de extrema importância para a atividade catalítica dessa endoprotease. Entretanto, o número de amostras foi pequeno e é possível que com um número maior alguma evidência para o desenvolvimento de formas graves em infecções assintomáticas possa ser observada. 


\section{CONCLUSÃO}

1. Nesse trabalho, o HRM não se mostrou adequado para a verificação de mutação no gene estudado;

2. O sequenciamento de Sanger, nesse caso, é melhor para a análise de mutação de um número pequeno de amostras;

3. Por sequenciamento, a gravidade da dengue não está relacionada com a presença de mutação na região dos aminoácidos "RGD" do domínio homo $B$ da endoprotease furina. 


\section{REFERÊNCIAS BIBLIOGRÁFICAS}

A Guide to High Resolution Melting (HRM) Analysis. Applied Biosystems.

ANDERSON, E. D., MOLLOY, S. S., JEAN, F., FEI, H., SHIMAMURA, S., AND THOMAS, G. (2002). The ordered and compartment-specific autoproteolytic removal of the furin intramolecular chaperone is required for enzyme activation. J. Biol. Chem. 277, 12879-12890.

BARROS, M. C. E. S. (2007). Expressão de proteínas do vírus da dengue em células de inseto utilizando o sistema baculovírus de expressão. Dissertação apresentada ao Departamento de Pós-Graduação em Patologia Molecular, da Faculdade de Medicina da Universidade de Brasília.

BHATT, S.; GETHING, P. W.; BRADY, O. J.; MESSINA, J. P.; FARLOW, A. W.; MOYES, C. L.; DRAKE, J. M.; BROWNSTEIN, J. S.; HOEN, A. G.; SANKOH, O.; MYERS, M. F.; GEORGE, D. B.; JAENISCH, T.; WINT, G. R. W.; SIMMONS, C. P.; SCOTT, T. W.; FARRAR, J. J.; HAY, S. I. (2013). The global distribution and burden of dengue. Nature.

Boletim epidemiológico, Guia de vigilância em saúde - Ministério da Saúde. (2016). Volume 47, número 20.

BRICKS, L. F. (2004). Vacinas para a dengue: perspectivas. Revisão e Ensaio. Instituto da Criança do Hospital das Clínicas da Faculdade de Medicina da Universidade de São Paulo.

CALVERT, A. E.; HUANG, C. Y. H., KINNEY, R. M.; ROEHRING, J. T. (2005). Nonstructural proteins of dengue 2 virus offer limited protection to interferon-deficient mice after dengue 2 virus challenge. Journal of General Virology.

CANSANÇÃO, I. F.; CARMO, A. P.; LEITE, R. D.; RABENHORST, S. H. (2016). Association of Polymorphisms in IL1 $\beta-511 \mathrm{C}>\mathrm{T}$, IL1RN 86 bp VNTR, and IL6 -174G>C Genes with Clinical Dengue Signs and Symptoms in Brazilian Dengue Patients. Viral Immunol.

CAPEDING, M. R.; TRAN, N. H.; HADINEGORO, S. R. et.al. (2014). Clinical efficacy and safety of a novel tetravalent dengue vaccine in healthy children in Asia: a phase 3 , randomised, observer-masked, placebo-controlled trial. Volume 384, Issue 9951, 11-17, Pages 1358-1365. 
CARDOSA, M. J.; HOOI, T. P.; SHAARI, N. S. (1988). Development of a dot enzyme immunoassay for dengue 3 : A sensitive method for the detection of antidengue antibodies. J Virol Methods; 22: 81 - 88.

CHEN, Y.; MAGUIRE, T.; HILEMAN, R. E.; FROMM, J. R.; ESKO, J.; LINHARDT, R. J.; MARKS, R. M. (1997). Dengue virus infectivity depends on envelope protein binding to target cell heparan sulfate. Nat Med. 3(8):866-71.

DOBROWOLSKI, S.; MCKINNEY, J.; AMAT DI SAN FILIPPO, C.; GIAK SIM, K.; WILCKEN, B.; LONGO, N. (2005) Validation of dye-binding/highresolution thermal denaturation for the identification of mutations in the SLC22A5 gene. Hum. Mutat. 25, 306-313

ERALI, M.; VOELKERDING, K. V.; WITTWER, C. T. (2008). High Resolution Melting Applications for Clinical Laboratory Medicine. Exp Mol Pathol. 85(1): 50-58. doi:10.1016/j.yexmp.2008.03.012.

GUBLER, D.K.G.; MARKOFF, L. (2007). Flaviviridae: The viruses and their replication. In Knipe DMH, Peter M. (ed.), Fields Virology, 5th Edition ed, vol. I. Lippincott Williams \& Wilkins.

GUBLER, D. J. (1998). Dengue and Dengue Hemorrhagic Fever. Clinical microbiology reviews. p. 480-496, volume 11 número 3.

Guia de Vigilância Epidemiológica - Ministério da Saúde. Secretaria de Vigilância em Saúde. Departamento de Vigilância Epidemiológica. (2005) Brasília - DF. 6ª edição. Série A. Normas e Manuais Técnicos.

GUNDRY, C., VANDERSTEEN, J., REED, G., PRYOR, R., CHEN, J., WITTWER, C. (2003) Amplicon melting analysis with labelled primers: a closed-tube method for differentiating homozygotes and heterozygotes. Clin. Chem. 49, 396-406

GUZMAN, M. G., AND G. KOURI. (1996). Advances in dengue diagnosis. Clin. Diagn. Lab. Immunol. 3:621-627.

HALSTEAD, S. B. (1997). Epidemiology of dengue and dengue hemorrhagic fever. In: Gubler DJ, Kuno G, Editors. Dengue and dengue hemorragic fever. New York: CAB International; p.23-44.

HALSTEAD, S. B. (2008). Dengue (Tropical Medicine/ Science and Practice - Vol. 5). Imperial College Press. 
HALSTEAD, S.B. (2003). Neutralization and antibody-dependent enhancement of dengue viruses. Advances in virus research 60:421-467.

HALSTEAD, S.B., DEEN J. (2002). The future of dengue vaccines. Lancet 360:12431245.

HATSUZAWA, K.; MURAKAMI, K.; NAKAYAMA, K. (1992). Molecular and Enzymatic Properties of Furin, a Kex2-Like Endoprotease Involved in Precursor Cleavage at ArgX-Lys/Arg-Arg Sites. J. Biochem. 111, 296-301.

HENCHAL, E. A.; PUTNAK, J. R. (1990). The dengue viruses. Clinical Microbiology Reviews. Volume 3(4), p. 376-396.

HEINZ, F.X., STIASNY, K. (2012). Flaviviruses and flavivirus vaccines. Vaccine 30:4301-4306.

HORSTICK, O.; TOZAN, Y.; WILDER-SMITH, A. (2015). Reviewing Dengue: Still a Neglected Tropical Disease? PLoS Negl Trop Dis 9(4): e0003632. doi:10.1371/journal.pntd.0003632

HRM Experiments - User guide, Applied Biosystems.

IHLE, M. A.; FASSUNKE, J.; KÖNIG, K.; GRÜNEWALD, I.; SCHLAAK, M.; KREUZBERG, N.; TIETZE, L.; SCHILDHAUS, H. U.; BÜTTNER, R.; MERKELBACHBRUSE, S. (2014). Comparison of high resolution melting analysis, pyrosequencing, next generation sequencing and immunohistochemistry to conventional Sanger sequencing for the detection of p.V600E and non-p.V600E BRAF mutations. BMC Cancer, 14:13.

Informe Semanal Dengue - Governo do Estado do Ceará, Secretaria da Saúde. (2013).

JANCIK, S.; DRABEK, J.; BERKOVCOVA, J.; XU, Y. Z.; STANKOVA, M.; KLEIN, J.; KOLEK, V.; SKARDA, J.; TICHY, T.; GRYGARKOVA, I.; RADZIOCH, D.; HAJDUCH, M. (2012). A comparison of direct sequencing, pyrosequencing, high resolution melting analysis, TheraScreen DxS, and the K-ras StripAssay for detecting KRAS mutations in non small cell lung carcinomas. J Exp Clin Cancer Res, 31:79.

KELLY, E. P.; GREENE, J. J.; KING, A. D.; INNIS, B. L. (2000). Purified dengue 2 virus envelope glycoprotein aggregates produced by baculovirus are immunogenic in mice. Vaccine, Volume 18, Issue 23, 22 May 2000, p.2549-2559. 
LEE, P.D., MUKHERJEE, S., EDELING, M.A., DOWD, K.A., AUSTIN, S.K., MANHART, C.J., DIAMOND, M.S., FREMONT, D.H., PIERSON, T.C. (2013). The Fc Region of an Antibody Impacts the Neutralization of West Nile Viruses in Different Maturation States. J. Virol. 87(24):13729. DOI: 10.1128/JVI.02340-13.

LEENEER, K.; COENE, I.; POPPE, B.; PAEPE, A.; ClAES, K. (2008). Rapid and Sensitive Detection of BRCA1/2 Mutations in a Diagnostic Setting: Comparison of Two High-Resolution Melting Platforms. Clinical Chemistry 54:6 982-989.

LEI, R.X., SHI, H., PENG, X.M., ZHU, Y.H., CHENG, J., CHEN, G.H. (2009). Influence of a Single Nucleotide Polymorphism in the P1 Promoter of the Furin Gene on Transcription Activity and Hepatitis B Virus Infection. Published online in Wiley InterScience (www.interscience.wiley.com). DOI 10.1002/hep.23062.

LI, L., LOK, S. M., YU, I. M., ZHANG, Y., KUHN, R. J., CHEN, J., ROSSMANN, M. G. (2008). The Flavivirus Precursor Membrane-Envelope Protein Complex: Structure and Maturation. Science 319, 1830.

LILJEQVIST, S.; STA으L, S. (1999). Production of recombinant subunit vaccines: protein immunogens, live delivery systems and nucleic acid vaccines. Review article. Journal of Biotechnology 73; 1-33.

LONIE, L., PORTER, D., FRASER, M., COLE, T., WISE, C., YATES. L., WAKELING, E., BLAIR, E., MORAVA, E., MONACO, A. and RAGOUSSIS, J. (2006) Determination of the mutation spectrum of the EXT1/EXT2 genes in British Caucasian patients with multiple osteochondromas, and exclusion of six candidate genes in EXT negative cases. Hum. Mutat. 27, 1160

LUSSON, J., BENJANNET, S., SAVARIA, M., CHRETIEN, M. AND SEIDAH, N. G. (1997). The integrity of the RRGDL sequence of the proprotein convertase PC1 is critical for its zymogen and C-terminal processing and for its cellular trafficking. Biochem. J. 326, 737-744.

MACKENZIE, J.S., GUBLER, D.J., PETERSEN, L.R. (2004). Emerging flaviviruses: the spread and resurgence of Japanese encephalitis, West Nile and dengue viruses. Nature medicine 10:S98-109.

MODIS, Y.; OGATA, S.; CLEMENTS, D. HARRISON, S. C. (2003). A ligand-binding pocket in the dengue virus envelope glycoprotein. Proceedings of the National Academy of Science of the United States of America. v. 100 (12), p. 6986-6991, 2003. 
NAKAYAMA, K. (1997). Furin: a mammalian subtilisin/Kex2p-like endoprotease involved in processing of a wide variety of precursor proteins, Biochem. J. 327, $625 \pm 635$.

NOMOTO, K., TSUTA, K., TAKANO, T., FUKUI, T., YOKOZAWA, K., SAKAMOTO, H., YOSHIDA, T., MAESHIMA, A., SHIBATA, T., FURUTA, K. et al. (2006) Detection of EGFR mutations in archived cytologic specimens of non-small cell lung cancer using high-resolution melting analysis. Am. J. Clin. Pathol. 126,

608-615

Public Immunization Starts. Disponível em: $\leq$ http://www.dengue.info/\#overlay=content/public-immunization-starts $>$ Acessado em 17/05/2016.

REED, G. H. AND WITTWER, C. T. (2004). Sensitivity and Specificity of SingleNucleotide Polymorphism Scanning by High-Resolution Melting Analysis. Clinical Chemistry, 50:10, 1748-1754.

REY, F. A. (2003). Dengue virus envelope glycoprotein structure: New insight into its interactions during viral entry. Virologie Moléculaire et Structurale, Unité Mixte de Recherche 24721157, Centre National de la Recherche Scientifique et Institut National de la Recherche Agronomique, 1 Avenue de la Terrasse, 91198 Gif-sur-Yvette Cedex, France.

RODENHUIS-ZYBERT, I.A.; VAN DER SCHAAR, H.M.; DA SILVA VOORHAM, J.M.; VAN DER ENDE-METSELAAR, H., LEI, H-Y, et al. (2010). Immature Dengue Virus: A Veiled Pathogen? PLoS Pathog 6(1): e1000718.

RODENHUIS-ZYBERT, I. A.; WILSCHUT, J.; SMIT, J. M. (2011). Partial maturation: an immune-evasion strategy of dengue virus? Review, Cell Press., Vol. 19, No. 5.

SEIPP, M. T.; DURTSCHI, J. D.; LIEW, M. A.; WILLIAMS, J.; DAMJANOVICH, K.; PONT-KINGDON, G., et al. (2007). Unlabeled oligonucleotides as internal temperature controls for genotyping by amplicon melting. J Mol Diagn;9:284 -9.

STEPHENSON, J. R. (2005). Understanding dengue pathogenesis: implications for vaccine design. Public Health Reviews.

TASSANEETRITHEP, B., BURGESS, T. H., GRANELLI-PIPERNO, A., TRUMPFHELLER, C., FINKE, J., SUN, W., ... MAROVICH, M. A. (2003). DC-SIGN 
(CD209) Mediates Dengue Virus Infection of Human Dendritic Cells. The Journal of Experimental Medicine, 197(7), 823-829. http://doi.org/10.1084/jem.20021840

TAKAHASHI, S., NAKAGAWA, T., KASAI, K., BANNO, T., DUGUAY, S.J., VAN DE VEN, W.J.M., MURAKAMI, K., NAKAYAMA, K. (1995). A Second Mutant Allele of Furin in the Processing-incompetent Cell Line, LoVo: Evidence for involvement of the homo B domain in autocatalytic activation. J. Biol. Chem. 1995, 270:26565-26569. doi: 10.1074/jbc.270.44.26565.

TAUIL, P. L. (2001). Urbanização e ecologia do dengue. Cad. Saúde Pública, Rio de Janeiro.

TIMERMAN, A.; NUNES, E.; LUZ, K. (2012). Dengue no Brasil - Doença urbana. 1aㅗ edição. Limay Editora. São Paulo - SP.

TIRADO, C.; YOON, K. J. (2003). Antibody-Dependent Enhancement of Virus Infection and Disease. Viral immunology. Volume 16, Number 1. Pp. 69-86.

WHO. Dengue: guidelines for diagnosis, treatment, prevention and control. TDR/World Health Organization. (2009).

WHO. Dengue, dengue haemorrhagic fever and dengue shock syndrome in the context of the integrated management of childhood ilness (Geneva, World Health Organization). (2005).

ZHONG, M.; BENJANNET, S.; LAZURE, C.; MUNZER, S.; SEIDAH, N. G. (1996). Functional analysis of human PACE4-A and PACE4-C isoforms: identification of a new PACE4-CS isoform. FEBS Letters 396, 31-36.

ZYBERT, I.A., ENDE-METSELAAR, H.V.D., WILSCHUT, J., SMIT, J.M. (2008). Functional importance of dengue virus maturation: infectious properties of immature virions. Journal of General Virology. 89, 3047-3051. 